Florida International University FIU Digital Commons

FIU Electronic Theses and Dissertations

University Graduate School

6-12-2013

\title{
Attributions and the Evaluation of Dynamic Performance
}

Michael B. Harari

mhara003@fiu.edu

DOI: $10.25148 /$ etd.FI13080903

Follow this and additional works at: https://digitalcommons.fiu.edu/etd

Part of the Industrial and Organizational Psychology Commons

\section{Recommended Citation}

Harari, Michael B., "Attributions and the Evaluation of Dynamic Performance" (2013). FIU Electronic Theses and Dissertations. 932. https://digitalcommons.fiu.edu/etd/932

This work is brought to you for free and open access by the University Graduate School at FIU Digital Commons. It has been accepted for inclusion in FIU Electronic Theses and Dissertations by an authorized administrator of FIU Digital Commons. For more information, please contact dcc@fiu.edu. 


\section{FLORIDA INTERNATIONAL UNIVERSITY}

Miami, Florida

ATTRIBUTIONS AND THE EVALUATION OF DYNAMIC PERFORMANCE

A thesis submitted in partial fulfillment of the

requirements for the degree of

MASTER OF SCIENCE

in

PSYCHOLOGY

by

Michael B. Harari

2013 
To: Dean Kenneth Furton

College of Arts and Sciences

This thesis, written by Michael B. Harari and entitled Attributions and the Evaluation of Dynamic Performance having been approved in respect to style and intellectual content, is referred to you for judgment.

We have read this thesis and recommend that it be approved.

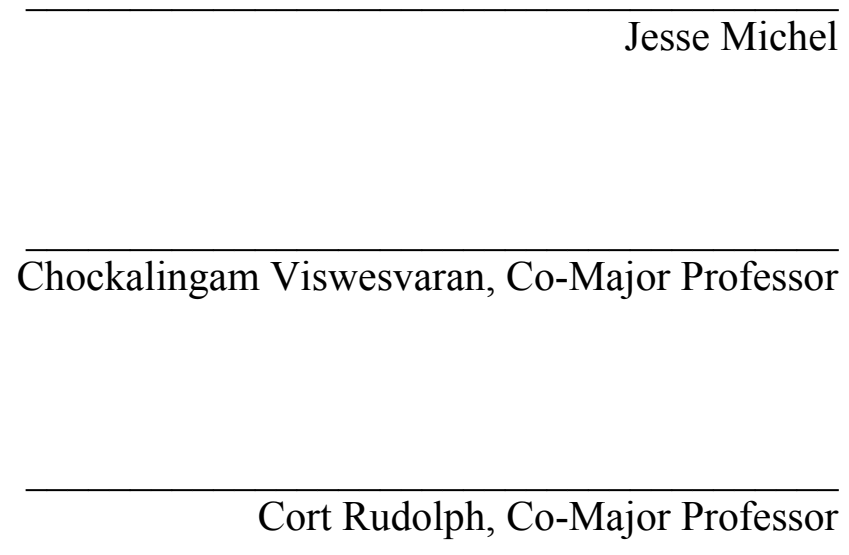

Date of Defense: June 12, 2013

The thesis of Michael B. Harari is approved.

\begin{tabular}{r} 
Dean Kenneth G. Furton \\
College of Arts and Sciences \\
\hline Dean Lakshmi N. Reddi \\
University Graduate School
\end{tabular}

Florida International University, 2013 


\title{
ABSTRACT OF THE THESIS \\ ATTRIBUTIONS AND THE EVALUATION OF DYNAMIC PERFORMANCE \\ by
}

\author{
Michael B. Harari \\ Florida International University, 2013 \\ Miami, Florida \\ Professor Chockalingam Viswesvaran, Co-Major Professor \\ Professor Cort Rudolph, Co-Major Professor
}

As research into the dynamic characteristics of job performance across time has continued to accumulate, associated implications for performance appraisal have become evident. At present, several studies have demonstrated that systematic trends in job performance across time influence how performance is ultimately judged. However, little research has considered the processes by which the performance trend-performance rating relationship occurs. In the present study, I addressed this gap. Specifically, drawing on attribution theory, I proposed and tested a model whereby the performance trend-performance rating relationship occurs through attributions to ability and effort. The results of this study indicated that attributions to ability, but not effort, mediate the relationship between performance trend and performance ratings and that this relationship depends on attribution-related cues. Implications for performance appraisal research and theory are discussed. 


\section{TABLE OF CONTENTS}

CHAPTER

PAGE

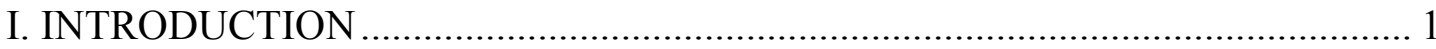

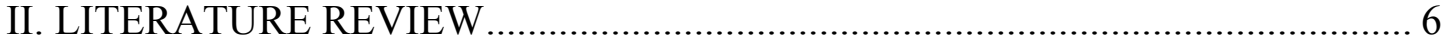

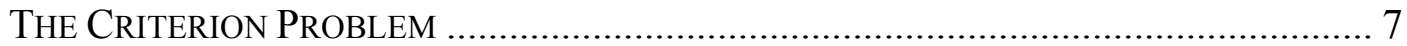

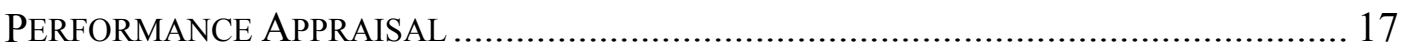

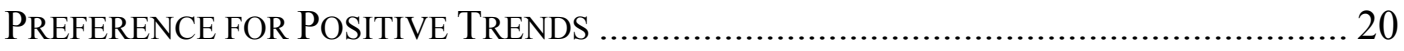

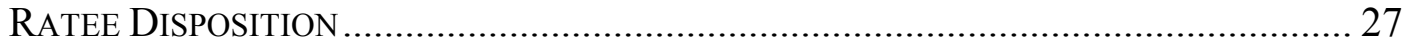

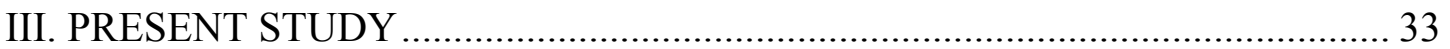

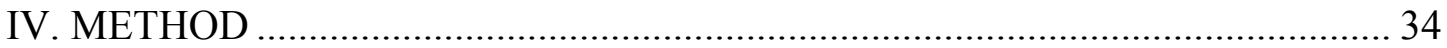

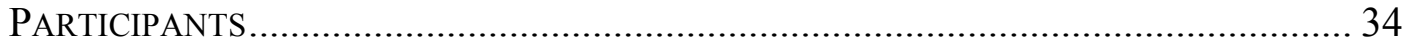

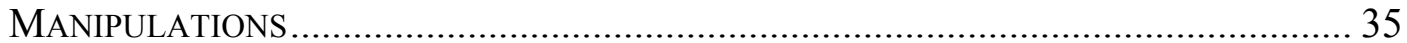

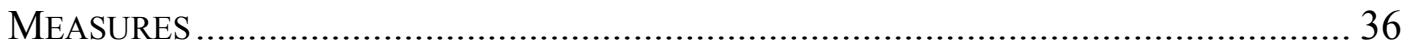

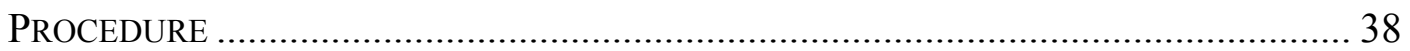

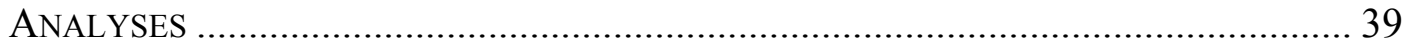

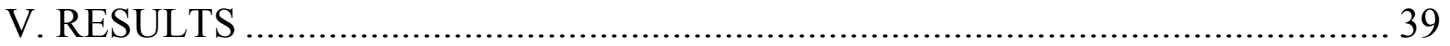

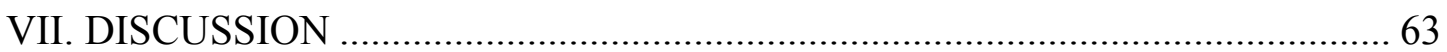

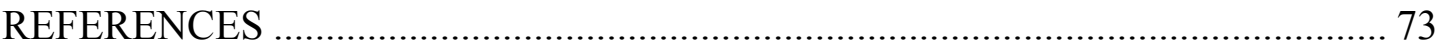

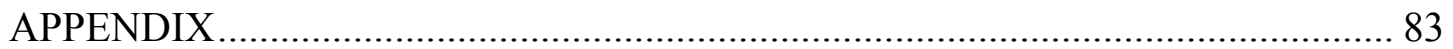




\section{LIST OF TABLES}

TABLE

PAGE

1. Internal-External and Stable-Unstable Causes of Performance Change............13

2. Descriptive Statistics for Study Variables by Condition..........................41

3. Means, Standard Deviations, and Intercorrelations Among Study Variables (Positive Trend Condition).

4. Means, Standard Deviations, and Intercorrelations Among Study Variables (Flat Trend Condition)

5. Means, Standard Deviations, and Intercorrelations Among Study Variables (Negative Trend Condition).....

6. Planned Contrasts for ANOVA Model Comparing Differences in Performance Ratings Across Trend Conditions.............................................. 44

7. Planned Contrasts for ANOVA Model Comparing Differences in Ability Attributions Across Trend Conditions.

8. Planned Contrasts for ANOVA Model Comparing Differences in Effort Attributions Across Trend Conditions.

9. Conditional Indirect Effects of Performance Trend on Performance Ratings Through Ability Attributions.

10. Conditional Indirect Effects of Performance Trend on Performance Ratings Through Ability Attributions. 


\section{LIST OF FIGURES}

FIGURE

PAGE

1. Positive, Negative, and Flat Performance Trends..............................

2. Graphical Depiction of Hypotheses and Relationships Being Tested................6

3. Main Effect of Performance Trend on Performance Ratings............................44

4. Main Effect of Performance Trend on Ability Attributions......................46

5. Main Effect of Performance Trend on Effort Attributions........................47

6. Results of Multiple Mediator Indirect Effects Model............................49

7. Main Effect of Cued Ability and Cued Effort on Performance Ratings...............52

8. Ability Cue by Effort Cue Interaction on Performance Ratings.................52

9. Main Effect of Ability Cue and Effort Cue on Ability Attributions................53

10. Main Effect of Ability Cue and Effort Cue on Effort Attributions................55

11. Performance Trend by Ability Cue Interaction on Performance Ratings.........57

12. Performance Trend by Effort Cue Interaction on Performance Ratings...........57

13. Performance Trend by Cued Ability by Cued Effort Interaction on Performance Ratings...............................................................58

14. Performance Trend by Ability Cue Interaction on Ability Attributions...........59

15. Performance Trend by Effort Cue on Effort Attributions.......................60

16. Conditional Indirect Effects Model........................................62 


\section{Attributions and the Evaluation of Dynamic Performance}

\section{Introduction}

Many methods of performance appraisal require job performance to be rated over a pre-defined time span (Thorndike, 1949). The most common methods require job performance at the overall or dimension level to be summarized as a single value (Ghiselli, 1956; Troops, 1944; Nagle, 1953). For example, Graphic Rating Scales present raters with statements related to overall or dimension-level job performance. Raters select the single value for each item that best represents the employee's performance over a specified time-span (Austin \& Villanova, 1992; Freyd, 1923; Paterson, 1923). However, these measures do not consider that job performance varies over time in often-systematic ways nor how this variation can influence performance ratings (Fisher, 2008; Reb \& Greguras, 2008).

For example, Hofmann, Jacobs, and Barata (1993) modeled individual-level job performance over 3 years. The results indicated that, while individual job performance over time can be described in terms of its mean value (i.e., static performance characteristics) it could also be described by its trend (i.e., dynamic performance characteristics; see also Deadrick, Bennet, \& Russell, 1997; Ployhart \& Hakel, 1998). Performance trend refers to the long-term, intra-individual trajectory of job performance (Reb \& Cropanzano, 2007). A performance trend (see Figure 1) can be positive (rising over time), negative (falling over time), flat, or nonlinear (e.g., quadratic, cubic). 
Figure 1

Positive, negative, and flat performance trends

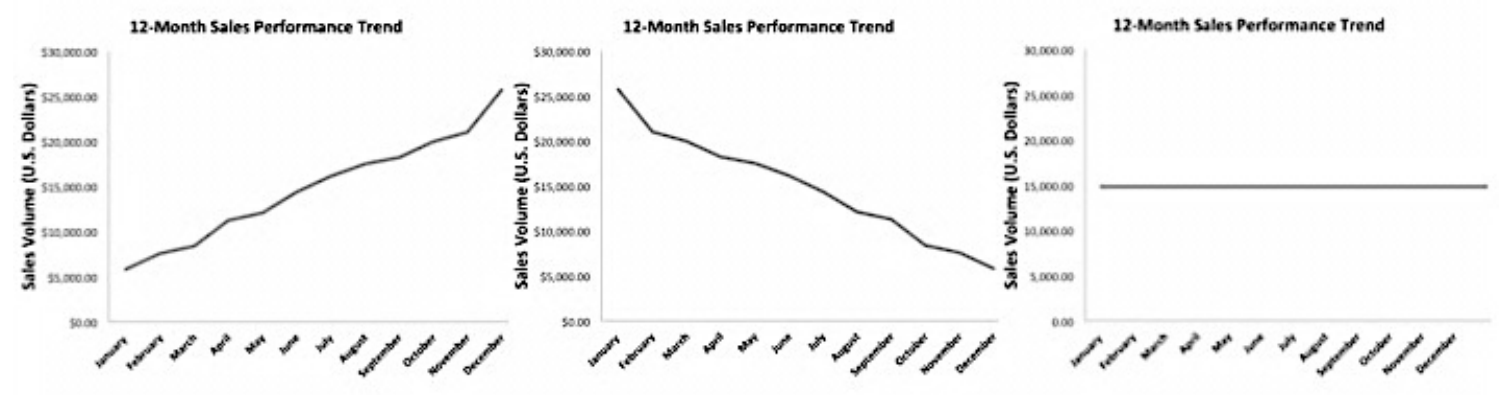

Research has considered how performance trend influences performance ratings (e.g., Scott \& Hamner, 1975; DeNisi \& Stevens, 1981). In a performance appraisal setting, raters subjectively judge the overall level of an employee's job performance and often quantify it as a single value. Judging performance is a cognitively complex task, as raters must integrate varying levels of performance into a single judgment (Feldman, 1981; Reb \& Cropanzano, 2007). One possibility is that raters average all of the employee's performance episodes exhibited over time and report this mean level performance as their overall rating (a performance episode refers to the smallest period of time in which job performance can be measured meaningfully; Stewart \& Nandkeolyar, 2006). However, research has demonstrated that this is not the case. DeNisi and Stevens (1981) conducted a laboratory experiment where they provided participants (raters) with graphic performance profiles. These graphs depicted objective performance of a hypothetical salesperson over time, visually displaying a performance trend. The participants were instructed to rate the performance depicted in the profile. The findings indicated that performance trend influenced performance ratings beyond the influence of mean performance levels alone. Specifically, positive trends were rated more favorably 
than negative trends, even when they had equal means. Subsequent studies have found similar results (e.g., Lee \& Dalal, 2011; Reb \& Cropanzano, 2007; Reb \& Greguras, 2010), demonstrating that when evaluating job performance, raters are influenced by salient features of the performance as a whole rather than by each performance episode equally (Ariely \& Carmon, 2000).

Building on the finding that performance trend influences performance ratings, research has begun to consider the processes responsible for the effect. Reb and Cropanzano (2007) proposed extrapolation as a potential mechanism. Extrapolation proposes that raters assume that a trend will continue in its general trajectory (Ariely \& Carmon, 2000). Thus a positive trend is anticipated to continue rising, which results in higher ratings, while a negative trend is anticipated to continue falling, which results in lower ratings. Reb and Greguras (2010) proposed and found some evidence for attributions as a dynamic performance sense-making mechanism. According to this theory, raters make sense of performance trends by inferring their causes (Green \& Mitchell, 1979). This is typically in terms of the ratee's disposition, particularly centered on their level of ability and effort (e.g., Heider, 1958; Jones \& Davis, 1966). Raters may infer from a positive trend that the ratee possess a high degree of ability and effort and from a negative trend that the ratee possess a low degree of ability and effort (Reb \& Greguras, 2010). These attributions may then influence performance ratings (e.g., Knowlton \& Mitchell, 1980; Weiner \& Kukla, 1970). For instance, Ashkanasy (1989) had participants read performance vignettes and indicate their attributions and performance ratings for each. The results indicated that, with few exceptions, the rater's 
attributions influenced their performance ratings. Hence, performance trends may influence performance ratings through their influence on attributions.

The findings of Reb and Greguras (2010) lend partial support to the attributional model of dynamic performance appraisal. Specifically, this research indicated that performance trend influences ability and effort attributions, such that positive trends influence attributions to greater levels of each than do negative trends. However, the influence of performance trend on performance ratings through attributions has yet to be demonstrated empirically. Thus, the purpose of my study is to address this gap by testing a model whereby performance trend influences performance ratings through attributions to ability and effort.

To bolster support for the proposed attributional model, I will manipulate cues related to the ratee's levels of ability and effort and assess their influence on attributions and performance ratings. Past research has referred to dispositional manipulations as manipulated attributions (e.g., Knowlton \& Mitchell, 1980; Tjosvold, 1985; Weiner \& Kukla, 1970). However, that description is a misnomer. As attributions are inferred from the behavior of others, they cannot be directly manipulated. Therefore, I will refer to these cues as "dispositional cues" or "cued dispositions." Prior research typically invokes the term disposition in relation to personality rather than internal attributes (e.g., Ackerman \& Heggestad, 1997). While these cues may technically reflect the ratee's attributes rather than dispositions, referring to "cued attributes" may become easily confused with attributions. Thus, going forward, I will use the term "disposition" to refer to experimentally manipulated ability and effort cues. 
These cued dispositions are hypothesized to moderate the relationship between performance trend and attributions to ability and effort. The cues will describe the ratee as possessing either: (a) high ability-high effort, (b) low ability-low effort, (c) high ability-low effort, and (d) low ability-high effort. Consistent with past attribution research (e.g., Knowlton \& Mitchell, 1980; Tjosvold, 1985; Weiner \& Kukla, 1970), I will test the direct effects of these cued dispositions, as well as their interaction with objective features of performance stimuli (i.e., direction of performance trend), on performance judgments. Additionally, I will test the main effect and interactions of these cues on ability and effort attributions, as well as their influence as moderators in the proposed indirect effect model.

Thus, the model proposed here suggests moderated-mediation (see Figure 2). Taken together, this study addresses the role of attributions in the performance trendperformance rating relationship by testing the indirect effect of performance trend on performance ratings through attributions. To bolster support for this model, I will be indirectly manipulating attributions using dispositional cues and measure their influence on subsequent performance ratings. I will utilize a 3 (performance trend: positive versus negative versus flat) x 2 (cued ability: high versus low) x 2 (cued effort: high versus low) between-subjects design and will measure ability attributions, effort attributions, and performance ratings. The results of the present study will advance the literature pertaining to the dynamic performance appraisal process and will also examine the generalizability of attributional models of performance appraisal to situations in which job performance is dynamic as opposed to static. 
Figure 2

Graphical depiction of hypotheses and relationships being tested

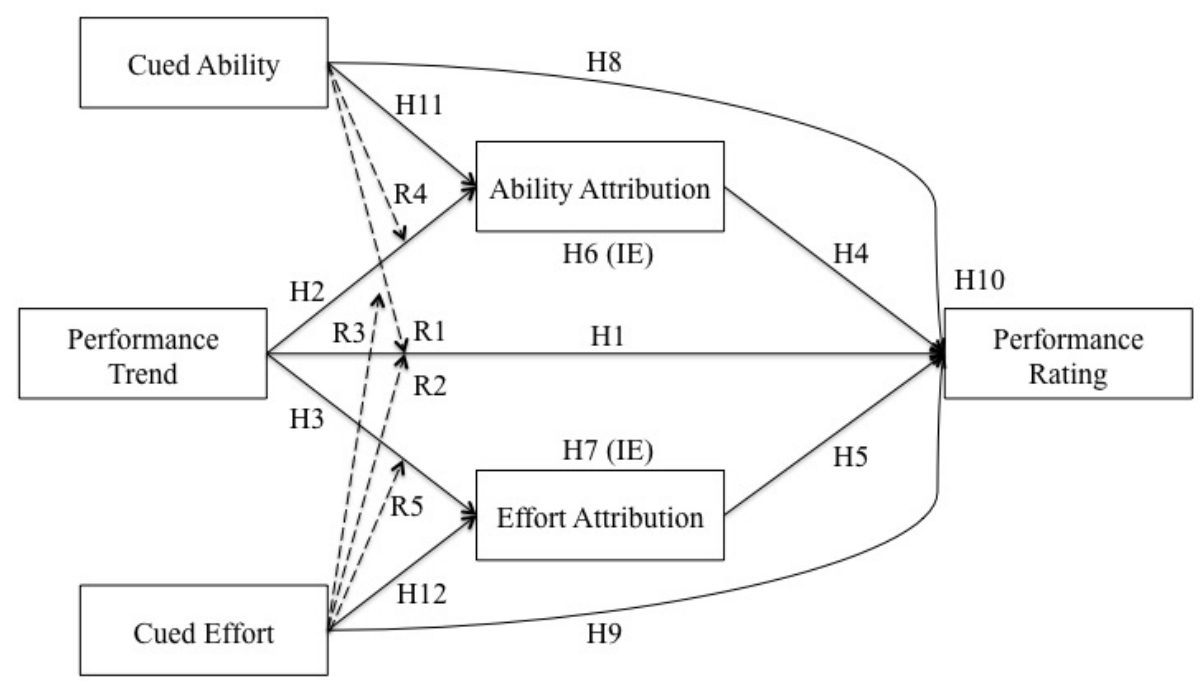

Note. Dashed lines indicate a moderation effect. $\mathrm{H}=$ hypotheses, $\mathrm{R}=$ research question, $\mathrm{IE}=$ indirect effect.

\section{Literature Review}

Job performance, defined as work-related behaviors that employees engage in, or outcomes that they bring about, scaled in terms of levels of proficiency, is an important construct in the organizational sciences (Viswesvaran \& Ones, 2000; Campbell, 1990). In an organizational setting, job performance ratings serve central purposes, as they aid in administrative decision-making, HR research, the feedback and development process, and the maintenance of adequate personnel records (Cleveland, Murphy, \& Williams, 1989). However, despite the importance of the job performance construct, there has been considerable debate surrounding its construct validity. These issues are collectively referred to as the criterion problem and are discussed below. 


\section{The Criterion Problem}

The criterion problem refers to the difficulty in adequately conceptualizing and measuring job performance (Flanagan, 1956; Landy \& Farr, 1983). The term is often invoked when discussing the pros and cons of the different job performance measures, most commonly classified as objective (nonjudgmental) or subjective (judgmental; Austin \& Villanova, 1992). Objective measures of job performance relate to outcomes and include production data (e.g., revenue generated, units produced) and employment data (absenteeism, turnover; Gaudet, 1963; Porter, Crampon, \& Smith, 1976). These measures are favorable as they are directly tied to organizational goals and success. However, these methods are often prone to criterion contamination and deficiency (Landy \& Farr, 1983). Criterion contamination occurs when performance unrelated variance is reflected in performance measures, while criterion deficiency occurs when performance related variance is absent from performance measures (Binning \& Barrett, 1989). For instance, Brogden and Taylor (1950) cite opportunity bias as a common source of contamination in objective performance measures. Opportunity bias occurs when factors beyond the employees' control, such as quality of sales territory or quality of production equipment, influence their criterion scores (Stewart \& Nandkeolyar, 2006). Additionally, objective performance outcomes are available only for a subset of jobs (Landy \& Conte, 2009). For example, managerial jobs do not results in such tangible outcomes as revenue generated and units produced.

Hence, the more common method of measuring job performance is judgmental ratings -- a subjective assessment of performance (i.e., subjective measure; Austin \& Villanova, 1992; Murphy \& Cleveland, 1995). Though overcoming some of the 
limitations of objective performance measures, this method still suffers from issues related to criterion contamination and deficiency, as well as from issues related to rater errors and biases (e.g., Borman, 1977; Cooper, 1981; Wherry \& Bartlett, 1982).

The criterion problem is also invoked when considering the temporal stability of job performance. That is, the extent to which an individual employee's job performance changes over time. As discussed by Ghiselli (1959), criteria had been considered static as a result of temporal stability being assumed rather than documented. However, according to Ghiselli, there is reason to believe that job performance does change over time -- an issue that came to be known as dynamic criteria and stirred a substantial debate in the literature (e.g., Austin, Humphreys, \& Hulin, 1989; Barrett, Caldwell, \& Alexander, 1985). The literature pertaining to dynamic criteria is reviewed in the proceeding sections.

Dynamic Criteria. Early research studied dynamic criteria as it relates to the following definitions: (1) changes in average group-level performance over time, (2) changes in predictor-criteria correlations (i.e., validity) over time, and (3) changes in the rank-ordering of criterion scores over time (Barrett et al., 1985; Bass, 1962; Ghiselli, 1956). Ghiselli and Brown (1947) studied the change in mean performance over seventeen months in a field sample of 94 streetcar motormen and operators (definition 1). Performance was operationalized as the number of accidents reported each month. The results indicated that performance improved at the group level over time (however, as noted by Barrett et al., group mean differences in performance across time is a conceptually weak definition of dynamic criteria and this study's findings are likely influenced by range restriction). 
Kaufman (1972) studied the change in predictor-criterion relationships over time in a sample of 110 engineers over 14 years (definition 2). The predictors studied were engineering interest (measured by the Ideas subscale of the ITME interest test) and ability (measured by the Engineering Achievement Test). Criterion scores over the 14-year period were averaged across three time periods, classified as early, middle, and recent. Additionally, three criterion measures were used: supervisory ratings, number of articles published, and number of patent disclosures. Results indicated that interests were significantly related to the number of patent disclosures during time periods 1 and 3 but not during time period 2. Similarly, ability was significantly related to the number of papers published during time periods 1 and 3 but not during time period 2. Results also indicated evidence of stability in the predictor-criterion relationship as ability was significantly related to the number of patent disclosures during all 3 periods.

Rambo, Chomiak, and Price (1983) examined the third definition of dynamic criteria (changes in rank-ordering of criterion scores over time). They collected the weekly output figures of 46 textile workers over 179 weeks. All of the employees included in this sample worked jobs that remained consistent over time. Additionally, none of the employees sampled were new to the job, so changes in performance cannot be due to learning. Finally, all of the employee's pay was based on their weekly production, helping to rule out job performance changing as a function of motivation (Rothe, 1978). Given these conditions, the authors anticipated that performance would remain stable over time. However, while the results did indicate some stability, the correlations between criterion scores decreased as the measurement occasions became further separated in time (i.e., simplex pattern). 
As the evidence for dynamic criteria grew, so did the debate surrounding it. Barrett et al. (1985) reviewed the dynamic criteria literature and ultimately determined that there was little conclusive evidence in favor of the phenomenon. The review by Barrett et al. sparked further debate (Austin, Humphreys, \& Hulin, 1989; Barrett \& Alexander, 1989). Hulin, Henry, and Noon (1990) helped to clarify the mixed findings by quantitatively summarizing the literature. They reported two meta-analyses -- one for changes in the predictor-criterion relationship over time (definition 2) and one for changes in criterion scores over time (definition 3). Their results served as evidence for the type of dynamic criteria initially proposed by Ghiselli (1956). When they regressed predictor-criterion correlations on time, results indicated that the average decrease in validity from the initial to the final performance was -.8 . When repeating this procedure for the change in criterion scores over time, results indicated that the average correlation decreased by -.6. The study of dynamic criteria advanced further as researchers began to study individual change patterns in job performance, known as intra-individual performance variability. (e.g., Deadrick et al., 1997; Hofmann et al., 1993; Thoresen, Bradley, Bliese, \& Thoresen, 2004; Zyphur, Chaturvedi, \& Arvey, 2008).

Intra-individual performance variability. Performance trend refers to the longterm trajectory of individual-level job performance over time (Reb \& Cropanzano, 2007). Linear performance trends can be classified as, for example, positive or negative. Positive trends are indicated by performance that improves over time, while negative trends are indicated by performance that declines over time (see Figure 1). The application of growth modeling to the longitudinal study of job performance allowed researcher to 
model performance trends empirically (e.g., Deadrick, Bennet, \& Russell, 1997;

Hofmann, Jacobs, \& Gerras, 1992; Hofmann et al., 1993; Ployhart \& Hakel, 1998).

Hoffmann et al. (1993) examined the performance trends of 300 insurance sales

agents over 12 quarters, operationalizing performance as monthly revenue generated. The authors used hierarchical linear modeling to estimate an intra-individual performance trend. Results indicated that $69 \%$ of the observed variance in intra-individual performance trend was systematic. Furthermore, they identified that performance trends differ in terms of their linear and non-linear (e.g., cubic, quadratic) trajectories. Deadrick et al. (1997) replicated these findings using the weekly output of 408 sewing machine operators. Using the same analytic strategy as Hoffmann et al., they found that performance trend accounted for $64 \%$ of the within-person variance in job performance (i.e., sewing output) in their sample.

Research has progressed further to identify antecedents of dynamic performance characteristics (i.e., the linear and non-linear properties of performance trend). The findings lend credence to the hypothesis that performance trends are meaningful and systematic, rather than purely the result of error and has specified that changes in performance result from factors that exist both internal and external to the employee, differing further in terms of their stability or predictability over time (Fisher \& Noble, 2004; Stewart \& Nandkeolyrar, 2006; Thoresen et al., 2004; Zyphur et al., 2008) Antecedents of intra-individual performance variability. All behavior exhibited by a given individual is not a pure expression of his or her own free will. Performance may be influenced by situational factors outside of an employee's control (Ajzen \& Fishbein, 2005; Roby, 1963), which refers to locus of causality, classifying 
causes of behavior as either internal or external to the actor. Internal refers to those causes that stem from within an individual (e.g., ability, motivation, affect), while external refers to those causes that stem from outside of an individual (e.g., task difficulty, opportunity to perform, luck).

Forces that influence performance also differ in terms of their predictability or temporal stability (Beal, Weiss, Barros, \& MacDermid, 2005; Fisher, \& Noble, 2004). Some behavioral determinants may be classified as stable, meaning they are relatively established and can be anticipated (e.g., ability, seasonal cycles). Other behavioral determinants may be classified as unstable, meaning they are relatively variable and cannot be anticipated (e.g., stress, affect, opportunity to perform). Antecedents of performance variability can be classified at the intersections of the stability and locus of causality dimensions, allowing us to depict performance variability as resulting from factors that are either: internal-stable, internal-unstable, external-stable, or externalunstable (see Table 1). 
Table 1

Internal-external and stable-unstable causes of performance variation.

\begin{tabular}{|c|c|c|}
\hline & Stable & Unstable \\
\hline Internal & 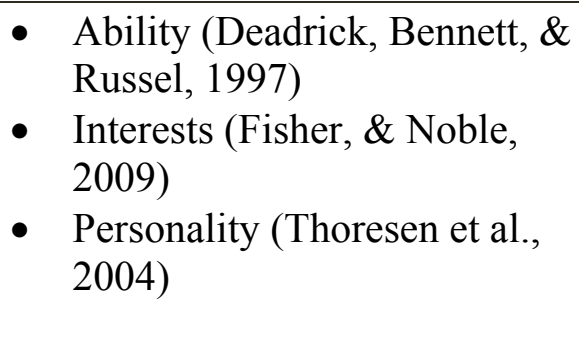 & $\begin{array}{ll}\text { - } & \text { Effort (Fisher, \& Noble, 2009) } \\
\text { - } & \text { Emotions (Fisher \& Noble, } \\
\text { 2009) } \\
\text { - } \\
\text { Affect (Beal, Weiss, Barros, \& } \\
\text { MacDermid, 2005; Ashkanasy \& } \\
\text { Humphrey, 2011) } \\
\text { - Mood (Miner \& Glomb, 2010) }\end{array}$ \\
\hline External & $\begin{array}{l}\text { - Difficulty (Fisher \& Noble, } \\
\text { 2009) } \\
\text { - Seasonal Cycles } \\
\text { - Consumer Demand }\end{array}$ & $\begin{array}{l}\text { Referrals (Stewart \& } \\
\text { Nandkeolyar, 2007) } \\
\text { - Encouragement (Guyatt et al., } \\
\text { 1984) } \\
\text { - Opportunity to perform }\end{array}$ \\
\hline
\end{tabular}

Internal-stable causes of within-person performance variability stem from aspects of the person that remain consistent over time. Personality and cognitive ability have been identified as internal-stable causes of performance variation. For example, Thoresen et al. (2004) conducted a longitudinal field study examining the relationship between personality and sales figures across four quarters of 48 pharmaceutical sales representatives. They found that agreeableness was positively related, and emotional stability was negatively related, to performance trend across the four quarters. Ployhart and Hakel (1998) examined the revenue generated by 303 securities salespersons over 8 consecutive quarters as a function of individual differences derived from biodata. The biodata measured, among other things, the salespersons self-reported empathy and persuasion. The findings of Ployhart and Hakel (1998) indicated that self-ratings of persuasion and empathy are both positively related to the slope of sales performance 
trends. Individual differences in ability are also positively related to performance trend. Using local validation data from the Virginia Employment Commission, Deadrick et al. (1997) assessed the relationship between cognitive ability (measured by the General Aptitude Test Battery) and the job performance of 408 sewing machine operators over 24 weeks. Job performance was operationalized as each sewing machine operator's average hourly production per week. They found that cognitive ability was positively related to performance trend, indicating that the employees with greater cognitive ability experienced more rapid improvements in performance (i.e., steeper positive trends) than the employees with lower cognitive ability.

Not all intrapersonal phenomena can be anticipated. The internal-unstable causes of within-person performance variability stem from aspects of the person that are not consistent over time, such as experiences of strain or fluctuations in affect or effort (Beal, Weiss, Barros, \& MacDermid, 2005; Ashkanasy \& Humphrey, 2011; Fisher \& Noble, 2004). Note that the conceptualization of effort as unstable used here differs from the trait perspective that may consider effort as a stable individual difference (i.e., conscientiousness). However, conceptualizing effort as unstable is consistent with the attribution literature (e.g., Knowlton \& Mitchell, 1980; Weiner \& Kukla, 1970).

Miner and Glomb (2009) employed experience sampling methodology to study the relationship between transitory mood and task performance of 49 call center trainees. Each participant was assigned a palmtop computer that prompted him or her to respond to items from the mood circumplex survey (Russell, 1980) in the morning and at 4 or 5 other, random times throughout the day. Task performance was operationalized as average call length from the 30-minute period in which the mood assessment had taken 
place (15-minutes prior to being surveyed, and 15-minutes after). The results indicated a negative relationship between mood and average call time during each 30-minute block -average call time was shorter when trainees were in a good mood. Thus, in this investigation, transitory mood was related to task performance, such that task performance was better when trainees were in a positive mood, versus a negative mood.

Other internal-unstable influences of performance variation include work experience and previous performance levels (Deadrick et al., 1997; Zyphur et al., 2008). Deadrick et al. (1997; described above in relation to cognitive ability) assessed the relationship between work experience and the performance trend of 408 sewing machine operators over a 24 -week period. They found that performance trend was negatively related to work experience, indicating that employees with more work experience demonstrated performance that improved more slowly than employees with less work experience.

External-stable causes of within-person performance variability stem from aspects of the situation that remain consistent and predictable over time, such as task difficulty or job complexity (Fisher \& Noble, 2004; Sturman, Cheramie, \& Cashen, 2005). Fisher and Noble (2004) used experience sampling methodology to examine the relationship between task difficulty and self-reported task performance in a sample of 121 employees, representing a broad range of organizations and occupations. Participants wore watches, which were programed to sound an alarm five times each working day. Upon hearing the alarm, participants were to respond to a brief questionnaire, which included a measure of task difficulty and task performance. Over the two-week data collection period, each participant was prompted to fill out the questionnaire up to 50 times. Results of this 
investigation indicated that task difficulty was negatively related to task performance. That is, as employees faced a more difficult task, they reported performing more poorly on it than an easier task. Additionally, Sturman et al. (2005) employed random-effects meta-analysis methodology to separate the variance in performance change over time that is due to measurement unreliability (i.e., test-retest) and to true changes in performance (i.e., stability). After separating job performance stability from test-retest reliability, they examined the influence of job complexity on performance stability over time. Results indicated that job complexity was negatively related to performance stability. That is, greater job complexity was associated with performance that is more variable over time, as opposed to lower job complexity, which is associated with job performance that is more stable over time.

The work environment is also filled with unanticipated factors that influence performance. The external-unstable causes of within-person performance variability stem from aspects of the work environment that are not consistent over time (Blumberg \& Pringle, 1982; Stewart \& Nandkeolyrar, 2006, 2007). For instance, Stewart and Nandkeolyrar (2006) examined the influence of environmental opportunity on variability in job performance in a sample of 167 sales representatives. They operationalized weekly sales performance as the dollar amount of revenue generated each week. They operationalized environmental opportunity as the number of referrals provided to the salesperson by the central office at the beginning of each week. Results indicated that $60.3 \%$ of the variation in weekly sales performance was attributable to referrals. Hence, variability in job performance is not always within the control of the employee. Table 1 
presents a non-exhaustive list of causes of within-person performance dynamics, classified in terms of stability and locus of causality.

At present, it has become well established the job performance across time can be characterized by dynamic characteristics (e.g., performance trend) in addition to static

characteristics (e.g., mean level). Furthermore, evidence documenting the antecedents of dynamic performance characteristics serves as further evidence that these properties are systematic rather than the result of error. Research has begun to consider how dynamic characteristics of job performance influence performance ratings. Below, I briefly review performance appraisal, followed by a review of the literature documenting the influence of performance trend on performance ratings.

\section{Performance Appraisal}

Performance appraisal is a formal process of evaluating and measuring job performance. A rater is the person (typically a supervisor) responsible for appraising the performance of an employee. A ratee is the employee whose performance is being appraised. Raters are to consider the ratee's job-relevant behaviors over a given time span and retrospectively judge its quality. Often, job performance becomes summarized as a single value, which is said to represent an employee's average or overall performance. However, in light of the dynamic properties of job performance, research is needed to understand how performance that changes over time is integrated into a global judgment. Furthermore, the evaluation of job performance is not limited to a formal performance appraisal context. Indeed, a number of workplace decisions involve the evaluation of job performance, and therefore understanding the processes by which job performance is 
evaluated is critical to advance our understanding of workplace decisions (Dalal et al., 2010).

Fisher (2008) argued that, as a result of cognitive limitations, raters might forget many discrete performance episodes when rating performance. Additionally, raters are to evaluate performance over a long period of time based on dimensions that are not naturally used to encode performance when initially observed. Hence, raters may cope poorly with the demands of aggregating varying performance levels into an overall judgment. As a result, raters may not equally weigh each performance episode when evaluating overall performance. Evidence indicates that this is the case (e.g., Scott \& Hamner, 1975; DeNisi \& Stevens, 1981; Reb \& Cropanzano, 2007; Lee \& Dalal, 2011). Research into dynamic performance appraisal has employed varies methodologies, but most common is to manipulate dynamics in job performance through graphic performance profiles. A graphic performance profile visually displays an employee's objective job performance (e.g., sales performance) over a time span (see Figure 1). By manipulating graphic performance profiles, researchers have demonstrated that dynamic performance characteristics (e.g., trend) impact overall performance ratings beyond the influence of static performance characteristics (e.g., mean) alone.

Models of performance appraisal have only recently begun to address how dynamics in job performance (specifically performance trend) can influence performance ratings. This research is reviewed in the proceeding section.

Dynamic Models of Performance Appraisal. Early work had conceptualized variability in performance as noise that distorted rater perceptions of mean performance levels (Scott \& Hamner, 1975; DeNisi \& Stevens, 1981). These researchers found that 
mean performance levels are the primary determinants of performance ratings. However, this research also found that performance trend exerted an incremental influence. Specifically, positive performance trends were rated more favorably than negative performance trends even when mean performance levels were identical.

Dynamic performance appraisal research was reinvigorated as dynamics in job performance began to receive greater empirical support (as described above; e.g., Hofmann et al., 1993; Ployhart \& Hakel, 1998). Recent research examining the influence of performance trend on performance ratings replicated and extended previous findings. Reb and Cropanzano (2007) found that participants rated performance the highest when it was characterized by an improving trend, followed by a u-shaped trend. Flat and inverted u-shaped trends were both rated lower than the u-shaped trend, but higher than a deteriorating trend. Furthermore, mean performance levels were held constant across conditions.

Reb and Greguras (2010) replicated the performance trend-performance rating relationship. In addition, they studied how rating purpose (administrative vs. developmental) might interact with dynamic and static performance characteristics to influence performance ratings. When ratings were being made for administrative reasons, mean performance had a larger affect than when the ratings were being made for developmental reasons. The reverse was true for trend, as it was weighed most heavily when the ratings were to be used for developmental purposes.

The impact of performance trend on performance ratings has been replicated in several subsequent studies (e.g., Lee \& Dalal, 2011; Barone \& DeCalro, 2012). At present, evidence indicates that performance trend is reflected in performance ratings. 
However, the manner in which raters use information related to performance trend when rating job performance remains unknown. To address this gap, researchers have considered several theoretical perspectives supporting the notion that positive trends are viewed more favorably than negative trends. I address these theoretical perspectives in the proceeding section.

\section{Preference for Positive Trends}

The task of evaluating a dynamic performance profile requires raters to make a retrospective summary evaluation (Ariely \& Carmon, 2000). Raters consider performance episodes that took place over a span of time and consolidate them into an integrated performance judgment. When retrospectively summarizing performance in this fashion, raters do not weigh each experience separately. Rather, they identify and use defining features to summarize the entire range of performance (Reb \& Cropanzano, 2007; Reb \& Greguras, 2008). The features that are selected from the event are referred to as salient Gestalt characteristics. Gestalt characteristics represent salient features of an experience, such as peak, end-point, and trend (Ariely, 1998; Kahneman, Fredrickson, Schreiber, \& Redelmeier, \& 1993). Raters may come to be influenced by these salient features because carefully considering each episode of any event when forming a summary judgment is cognitively burdensome and raters may be unwilling or unable to expend this effort (Feldman, 1981; Reb \& Cropanzano, 2007). On the other hand, representing an experience based on a few salient features is far more practical and cognitively efficient. Research into Gestalt characteristics, in line with findings related to judging dynamic performance, has found a consistent tendency for positive trends to be 
evaluated more favorably than negative trends (Loewenstein \& Prelec, 1991, 1993). Theoretical explanations for why this may be so are reviewed below.

Contrast Effects. Early job performance sets up expectations for future job performance (DeNisi, Cafferty, \& Meglino, 1984; Ilgen \& Feldman, 1983). When future job performance is discrepant from the rater's expectations, a contrast effect can occur. A contrast effect biases the rater's performance judgment away from prior performance levels (Sherif \& Cantril, 1945). For example, Murphy, Balzer, Lockhart, and Eisenman (1985) conducted a laboratory experiment where participants viewed and rated a videotaped lecturer delivering an average performance (where the lecturer adopted an average speaking style that was neither dynamic nor hesitant). Before watching this average performance, participants watched the same lecturer deliver either a below average (poor condition) or above average (good condition) lecture. The results indicated a contrast effect; participants in the poor condition rater the average performance video significantly higher than participants in the good condition. That is, participants in the poor condition came to expect poor performance. As later performance deviated from this expectation in a favorable direction, the later performance was perceived favorably. On the other hand, participants in the good condition came to expect good performance. As later performance deviated from this expectation in an unfavorable direction, the later performance was perceived unfavorably.

Contrast effects may help explain a preference for positive trends. As a positive trend begins with poor performance, raters may come to expect poor performance. As performance rises, it violates the rater's expectations in a favorable direction and is thus rated more favorably. On the other hand, a negative trend begins with favorable 
performance, setting the raters expectations that this will continue. As performance declines, it violates the rater's expectations in an unfavorable direction and is thus rated less favorably.

Extrapolation. Raters may rate positive trends more favorably than negative trends because raters mentally project the trend continuing in its general trajectory into the future -- a process known as extrapolation (Ariely \& Carmon, 2000). When evaluating a performance trend in this fashion, raters make use of the anchoring-andadjustment heuristic to infer future data points (Kahneman \& Tversky, 1973). Accordingly, raters mentally calculate the slope of the performance trend. Then, using the last data point as an anchor (the point from which the projection is made), they use the previously calculated slope to extend the final data point into the future (i.e., adjustment; Jones, 1979).

Barone and DeCarlo (2012) tested this proposition empirically in a lab study. The participants were 154 sales managers who evaluated a hypothetical salespersons performance profile. The performance profile depicted monthly sales performance over a full calendar year and was characterized by a positive trend. After reviewing the profile, participants indicated their evaluation of the salesperson's performance (ranging from "worst performance" to "best performance") and their expectations for the salesperson's performance 6 months into the future (ranging from "worst performance next year" to "best performance next year"). As predicted, mediation analyses revealed that performance trend influenced performance ratings through expectations for future performance. 
Attribution Theory. Trends might also influence judgments by prompting observers to consider their antecedents (i.e., attributions; Reb \& Greguras, 2010). Attributions refer to the processes of constructing explanations for observed phenomenon. They stem from a motivation for people to understand and predict the events around them, leading them to a search for the causes of events (Heider, 1958; Baumeister, 1991; Frankl, 1963). According to Kelley's $(1972,1973)$ attribution theory, a rater will arrive at an attribution for ratee performance by considering its distinctiveness, consistency, and consensus. Distinctiveness refers to whether the same performance level occurred on a variety of tasks or on a single task. Consistency refers to whether or not the ratee exhibited the same performance level across contexts and time. Consensus refers to whether or not other ratees (subordinates) perform similarly to the ratee. The rater uses these dimensions to deduce what caused the ratee's performance (i.e., to arrive at an attribution)

However, raters do not always possess the time or motivation to form an attribution so carefully (Gilbert, Pelham, \& Krull, 1988). Rather, they may often come to rely on causal schemata -- rules of thumb used to judge cause and effect (Kelley, 1972). A common causal schemata used in performance-related situations relates to the dimensions of ability, effort, task difficulty, and luck (Weiner, Frieze, Kukla, Reed, Nest, \& Rosenbaum, 1972). These dimensions are particularly relevant in a performance appraisal setting (Green \& Mitchell, 1979). For example, Reb and Greguras (2010) conducted a within-subjects laboratory experiment where each participant rated several dynamic performance profiles. Without being provided any information aside from the profiles, participants were to rate the hypothetical salespeople's traits. Results indicated 
that hypothetical salespeople whose performance profiles represented a positive trend were perceived as possessing greater levels of ability and effort than hypothetical salespeople whose performance profiles represented a negative trend. Attributions to task difficulty and luck are less common due to a phenomenon known as the fundamental attribution error (also known as the correspondence bias; Gilbert \& Malone, 1995). The crux of this phenomenon is that observers tend to believe that the behavior exhibited by an individual is a function of their enduring dispositions rather than situational opportunities or constraints. The result is that attributions to ability and effort (internal attributions) are much more common than attributions to task difficulty and luck (external attributions).

In light of these findings, I hypothesize the following in relation to performance trend, attributions to ability and effort, and performance ratings:

Hypothesis 1: Job performance trends influence job performance ratings such that positive performance trends are associated with the highest performance ratings, followed by flat performance trends, followed by negative performance trends.

Hypothesis 2: Job performance trends influence ability attributions such that positive performance trends are associated with the highest ability attributions, followed by flat performance trends, followed by negative performance trends. Hypothesis 3: Job performance trends influence effort attributions such that positive performance trends are associated with the highest effort attributions, followed by flat performance trends, followed by negative performance trends. 
Research also supports the idea that raters use attributions to make sense of and evaluate ratee performance (Green \& Mitchell, 1979). Ashkanasy (1989) demonstrated this relationship in a laboratory study. Two hundred and eighty-eight participants read 16 performance vignettes. After reading each one, they indicated the hypothetical employee's levels of ability, effort, task difficulty, and luck. Finally, they evaluated the employee on the basis of the following variables: expectations for future performance on the same task, aspiration, need for close supervision in the future, and immediate reward/punishment response toward the subordinate. Results indicated that when the employee performed successfully, all of the attributions influenced all of the evaluation variables (with the exception of task difficulty and luck on reward response). When the employee performed unsuccessfully, some of the relationships observed in the successful conditions were also observed. Ability and task difficulty influenced expectations for future performance and effort influenced the need for close supervision in the future. In general, these results and those of several subsequent studies (e.g., Ashkanasy, 1995; Tjosvold, 1985; see Martinko, Harvey, \& Douglas, 2007 for a review) support the proposition that attributions influence performance evaluations.

In light of these findings, I predict that ability and effort attributions will both be positively related to performance ratings. Additionally, as ability and effort attributions are likely correlated, in order to justify studying the relationship of both as antecedents to performance judgments, I will demonstrate that ability and effort attributions each account for unique variance in performance judgments, above and beyond one another and performance trend.

Hypothesis 4: Ability attributions are positively related to overall performance 
ratings when controlling for the influence of performance trend and effort attributions.

Hypothesis 5: Effort attributions are positively related to overall performance ratings when controlling for the influence of performance trend and ability attributions.

Finally, despite the relationship demonstrated between (a) dynamic performance characteristics and attributions (Reb \& Greguras, 2010) and (b) attributions and performance ratings (e.g., Ashkanasy, 1989, 1995; Knowlton \& Mitchell, 1980; Tjosvold, 1985), the extent to which attributions explain a preference for positive performance trends over negative performance trends remains unexplored. Given the literature reviewed above, I intend to fill this gap, formally hypothesizing the following:

Hypothesis 6: The relationship between performance trend and performance rating is mediated by ability attributions, such that performance trend positively influences ability attributions, which positively influences performance ratings. Hypothesis 7: The relationship between performance trend and performance rating is mediated by effort attributions, such that performance trend positively influences effort attributions, which positively influences performance ratings.

To bolster support for the proposed model, I will introduce an experimental manipulation intended to influence the mediator (in this case, attributions to ability and effort) and demonstrate that influencing the mediator influences the outcome (in this case, performance ratings). I accomplish this by manipulating dispositional cues related to the ratee's levels of ability and effort and testing their main effects and interactions on performance judgments, ability attributions, and effort attributions. I will also explore 
interactions between cued ability, cued effort, and performance trend on the three dependent variables, as well as the cued dispositions as moderators for the mediation model discussed earlier.

In the proceeding section, I will review several theoretical perspectives related to how cued dispositions influence performance ratings and attributions to ability and effort. The research reviewed below was done primarily within a static performance framework (e.g., Cardy \& Dobbins, 1986; Knowlton \& Mitchell, Weiner \& Kukla, 1970). That is, performance information was related to overall level of performance rather than dynamic characteristics such as trend. Therefore, I will contribute to the literature by updating this line of research to consider the influence of rating dynamic versus solely static performance, as well as further demonstrating the role of attributions in the evaluation of dynamic performance.

\section{Ratee Disposition}

Raters are influenced by the ratee's disposition when rating performance (Cardy \& Dobbins, 1986; Ensher \& Murphy, 1997; Turban \& Jones, 1988; Wherry \& Fryer, 1949). For example, performance ratings are influenced by interpersonal affect, or how likeable the ratee is. Conway (1998) demonstrated this by analyzing a published Multitrait Multirater covariance matrix. The original study (Tucker, Cline, \& Schmitt, 1967) included supervisor and peer ratings for three dimensions of performance. They also reported supervisory ratings of overall performance and likeability. Conway conducted a CFA on the MTMR matrix, partitioning dimension and method variance, and fixing dimension-factor loadings and dimension-factor correlates to these values to test the influence of likeability on supervisory ratings. Results indicated that affect (or liking) 
accounted for $23 \%$ of supervisor method variance in performance ratings. Research has also demonstrated this relationship when the ratee's disposition is cued via experimental manipulation. Several theoretical perspectives relating to this effect are reviewed below.

Assimilation Effects. As discussed earlier, a contrast effect occurs when prior judgments are biased away from previous information. An assimilation effect refers to the opposite -- prior judgments are biased towards previous information (Sherif \& Cantril, 1945). Smither, Reilly, \& Buda (1988) demonstrated that when information was observed directly, a contrast effect was likely to occur. However, when information was received second hand, an assimilation effect was typical. They used the same stimuli as the Murphy et al. (1985) study described earlier in relation to contrast effects. Participants were to observe and rate a videotaped lecture depicting average performance. Before doing so, participants were assigned to the good condition, where they observed the same lecturer performing above average, or to the poor condition, where they observed the same lecturer performing below average. Smither et al. (1988) added an additional independent variable, direct versus indirect observation. In the direct observation condition, participants observed the good or poor performance on a video tape as was done in the original study. In the indirect observation condition, participants received second-hand accounts of the good or poor performance by reviewing the average ratings of participants in the direct observation condition. Participants in both the direct and indirect observation condition observed the final, average performance directly. Results indicated that participants in the direct condition rated the average performance higher when it was preceded by poor performance rather than by good performance (i.e., contrast effect). Conversely, participants in the indirect condition rated the average 
performance higher when it was preceded by good performance rather than by poor performance (i.e., assimilation effect).

Assimilation effects may help to explain why dispositional cues can influence performance ratings. When cues are favorable (e.g., high ability and/or high effort), ratings may assimilate to these cues and become more positive. On the other hand, when cues are unfavorable (e.g., low ability and/or low effort), ratings may assimilate to these cues and become more negative.

Impression Formation. The impression formation literature has long-since considered how people use dispositional cues when judging another person (e.g., Anderson, 1965; Feldman, 1966; Wyer \& Hinkle, 1971). Like other areas (e.g., attributions), performance judgments in this field typically center on ability and effort (e.g., Surber, 1984; Waldmann, 2007). From the perspective of impression formation, raters integrate ability and effort cues by engaging in cognitive algebra; that is, they algebraically combine certain features of the stimulus person (e.g., their ability and effort) to arrive at a judgment of their performance. Anderson and Butzin (1974) studied this phenomenon to determine how people integrate ability and effort information when judging performance. In a laboratory study, they provided participants with cues related to either an athlete or a student's levels of ability and effort. Solely on the bases of this information, participants were asked to judge the stimulus person's performance. Results indicated that participants considered both ability and effort as important and equal determinants of another person's performance, as their judgments followed a multiplicative rule (i.e., performance $=$ ability $\mathrm{x}$ effort). Hence, ability and effort cues are both perceived as meaningful antecedents of another person's performance. 
Judgment of Responsibility. Research has considered how beliefs concerning the causes of an actor's behavior influence subsequent behavior towards that person through their effects on responsibility judgments (also known as attribution of responsibility or attribution of intent; Schmitt, 1964; Tietze \& Lewit 1969). While an attribution concerns the cause of a behavior, a responsibility judgment concerns whether or not the actor is held responsible for that behavior (Weiner, 1995). A responsibility judgment typically surrounds the intent or controllability of a behavior, thus an important distinction is made between "can" (i.e., ability) and "try" (i.e., effort; Schmitt, 1964).

Effort results in more extreme performance evaluations than ability, as effort is a controllable trait (Weiner \& Kukla, 1970). That is, when a person fails due to a lack of effort, they are held responsible for their poor performance and are rated poorly. However, when the same poor performance is due to a lack of ability, they are not held responsible for their poor performance, as their ability level is outside of their control, and are rated more favorably. Knowlton and Mitchell (1980) demonstrated this in a lab study. The participants were to supervise three subordinates (confederates who were ostensibly randomly assigned to the subordinate condition) as they coded survey data. Knowlton and Mitchell manipulated the subordinate's ability, effort, and overall performance level. The subordinate's Wonderlic score served as the ability manipulation. The number of breaks taken by each subordinate served as the effort manipulation. The number of surveys coded as well as the number of mistakes made served as the performance manipulation. The four conditions tested in this study were (1) high performance, high ability, average effort, (2) high performance, average ability, high effort, (3) low performance, low ability, average effort, and (4) low performance, average 
ability, low effort. After the supervising task was complete, the participants rated each subordinate using a six-item rating scale, which was summed across items. The results of this study indicated that high performance was always rated higher than low performance. However, low performance was rated more favorably when it was seen as resulting from low ability than low effort. Additionally, high performance was rated more favorably when resulting from high effort and low ability than when resulting from high ability and low effort.

Given the research explained above, I hypothesize the following concerning the influence of manipulated cued ability and manipulated cued effort on the three judgmental outcomes in this study (i.e., performance ratings, ability attributions, and effort attributions):

Hypothesis 8: Cued ability is positively related to performance ratings.

Hypothesis 9: Cued effort is positively related to performance ratings.

Hypothesis 10: The relationship between cued ability and performance ratings is moderated by cued effort, such that the relationship is stronger when cued effort is high.

Hypothesis 11: Cued ability is positively related to ability attributions.

Hypothesis 12: Cued effort is positively related to effort attributions.

Furthermore, as research indicates an interaction between observed performance levels (or associated performance outcomes; e.g., good/bad, success/failure) and cued dispositions on performance ratings, I expect to find two and three way interactions between performance trend, cued ability, and cued effort on (a) performance ratings, (b) ability attributions, and (c) effort attributions. Prior research has considered these 
relationships in terms of static performance indices (e.g., mean level performance, success versus failure; Weiner \& Kukla, 1970). In the case of varying performance trends, this relationship may be far more complex. For instance, when a worker who is described as demonstrating high ability and high effort's performance declines over time, the rater may react in several different ways. The rater may assimilate to the dispositional cue and perceive that the declining trend reflects favorable performance; perhaps inferring that the task had been increasing in difficulty or other situational factors had resulted in the performance decline (Gilbert \& Malone, 1995; Smither et al., 1988). On the other hand, the rater may correct their initial attributions and decide that the ratee's ability and effort is not so high after all (Gilbert et al., 1988). Therefore, I do not generate any hypotheses for the following interactions: (a) cued ability by performance trend, (b) cued effort by performance trend, and (c) performance trend by cued ability by cued effort on (a) performance ratings, (b) ability attributions, and (c) effort attributions. Also, I also propose no formal hypotheses for the conditional indirect effect of dispositional cues on the proposed model, and examine this effect as a research question. However, I do speculate that the indirect effect of performance trend on performance judgments through attributions will be strongest when cued ability and effort are both high, as these cues would reinforce the attributions that people naturally form (Reb \& Greguras, 2010). Formally stated:

Research Question 1: Is there a performance trend by cued ability interaction on performance ratings?

Research Question 2: Is there a performance trend by cued effort interaction on performance ratings? 
Research Question 3: Is there a performance trend by cued ability by cued effort interaction on performance ratings?

Research Question 4: Is there a performance trend by cued ability interaction on ability attributions?

Research Question 5: Is there a performance trend by cued effort interaction on effort attributions?

Research Question 6: Is the indirect effect of performance trend on performance ratings through ability and effort attributions conditional upon dispositional cues?

\section{Present Study}

In summary, the present study is intended to test a model whereby performance trend influences performance ratings through attributions to ability and effort (see Figure 2). Furthermore, I intend to bolster support for the proposed model by manipulating cues that are anticipated to influence ability and effort attributions. Thus, by indirectly manipulating ability and effort attributions and assessing their influence on performance ratings, I will garner additional support for the proposed model. I will accomplish this by means of a 3 (performance trend: positive versus negative versus flat) x 2 (cued ability: high versus low) x 2 (cued effort: high versus low) design. I will collect measures of ability attributions, effort attributions, and overall performance ratings, as well as manipulation checks intended to test the efficacy of the performance trend and cued disposition manipulations. 


\section{Method}

\section{Participants}

I recruited participants from undergraduate psychology courses at a large, public university in the southeastern United States $(N=526)$. In terms of gender, $24 \%$ of participants were male and $76 \%$ of participants were female. In terms of race, $13.6 \%$ of participants were White/Caucasian, 7.3\% were African American, 69.9\% were Hispanic, $3.1 \%$ were Asian, .2\% were Native American, .4\% were Pacific Islander, and the remaining 5.6\% indicated "Other." A majority of participants (87.2\%) were currently employed, with only $12.8 \%$ indicating that they were currently unemployed. Approximately half of the sample (49.1\%) indicated that they have had the authority to evaluate other people's performance at work, while the remaining $50.9 \%$ indicated that they have not.

The use of student samples in performance appraisal research is commonly criticized as lacking generalizability to working populations (cf. Landy, 2008). To address such concerns, and consistent with the recommendations of Highhouse and colleagues (Highhouse, 2009; Highhouse \& Gillespie, 2009), I assessed the extent to which employment status (i.e., employed vs. unemployed) influenced the dependent variables in this study as well as the relationships between the independent and dependent variables. Specifically, I specified a 3 (performance trend: positive versus negative versus flat) x 2 (cued ability: high versus low) x 2 (cued effort: high versus low) x 2 (employment status: employed versus unemployed) between-subjects MANOVA model in which performance ratings, ability attributions, and effort attributions were the dependent variables. The results indicated that the main effect of employment status on 
the linear combination of the dependent variables was not statistically significant $\left[\lambda_{\text {Wilks }}=\right.$ $\left.1.0, \mathrm{~F}(3,496)=1.30, p>.05 ; \eta_{\text {partial }}^{2}=.01\right]$, nor was the trend by employment status interaction $\left[\lambda_{\text {Wilks }}=.99, \mathrm{~F}(6,992)=.98, p>.05 ; \eta^{2}\right.$ partial $\left.=.01\right]$, the cued ability by employment status interaction $\left[\lambda_{\text {Wilks }}=.99, \mathrm{~F}(3,496)=.28, p>.05 ; \eta^{2}\right.$ partial $\left.=.00\right]$, or the cued effort by employment status interaction $\left[\lambda_{\text {Wilks }}=1.0, \mathrm{~F}(3,496)=.28, p>.05 ; \eta^{2}\right.$ partial $=.01]$. These patterns of results suggest that the process by which participants approached the experimental task did not systematically differ between employed versus unemployed participants. The pattern of results observed here strengthens confidence in the generalizability of this study's findings. However, I note that this does not imply that the findings of this study will generalize to a performance rating scenario in an actual organization -- only that the process that I am examining in the laboratory study here does not seem to differ between employed vs. unemployed students.

\section{Manipulations}

Performance Profiles. I used three graphical performance profiles, depicting sales volume for a hypothetical salesperson over a twelve-month period (see Figure 1). To create the positive and negative performance profiles, I created a vector of 12 numbers randomly drawn from a normal distribution with a mean of 5 and a standard deviation of 1.5. I then added this vector to a second vector of 12 scores that started with 1.5 and increased by a factor of 1.5 to arrive at 18 . Each score in the resulting vector was then multiplied by 1,000 and sorted from lowest to highest (to create a positive trend) and highest to lowest (to create a negative trend). Across both conditions, the mean level of performance and the standard deviation of performance across the twelve-month period were held constant at $\$ 14,827.07(\mathrm{SD}=\$ 6,018.63)$. To create the flat performance 
profile, I created a profile in which every data point was equal to $14,827.07$-- the mean of the performance profiles depicted in the positive and negative trend manipulations.

Dispositional Cues. I manipulated the ratee's disposition using four vignettes designed to fully cross high and low levels of ability with high and low levels of effort (see Appendix A). The vignettes were depicted as comments from the ratee's direct supervisor, which described him as demonstrating either: (a) high ability-high effort, (b) high ability-low effort, (c) low ability-high effort, or (d) low ability-low effort. Ability is manipulated by describing the ratee as possessing either high or low competence, talent, and aptitude. Effort is manipulated by describing the ratee as possessing either high or low ambition, determination, and drive. The adjectives chosen as synonyms of ability and effort were prescreened in another study.

\section{Measures}

Attributions. I measured attributions using the ability and effort subscales of the Multidimensional Observer Attributions for Performance Scale (MOAPS; Rutherford, Harari, \& Rudolph, 2013; see Appendix B). The MOAPS was developed on the basis of the Multidimensional-Multiattributional Causality Scale (MMCS; Lefcourt, Von Baeyer, Ware, \& Cox, 1979). The development of the MOAPS began by creating six item stems, each beginning with "This person's performance..." (i.e., reflects that they ...; is a direct result of...; is probably due to...; is likely influenced by...; may be due to...; has a lot to do with...). Each of these items is adapted to each attribution dimension measured by the scale (e.g., ability, effort) by completing the item with the respective attribution dimension or a synonym. The scale asks six items related to ability (e.g., This person's performance is a direct result of their competence) and six items related to effort (e.g., 
This person's performance is a direct result of their efforts). Responses were recorded on a 7-point Likert scale ranging from "Strongly Disagree" to "Strongly Agree." Coefficient alpha reliability estimates for the ability and effort subscales were adequate ( $a=.90$ and .86 , respectively).

Subjective Performance Ratings. To collect ratings of overall job performance, I used a three-item scale from Nieminen, Rudolph, Baltes, Capser, Wynne, \& Kirby (2013; see Appendix C). The scale was developed to rate the performance of managers and thus required a slight modification - changing "manager" to "sales manager." A sample item is “Overall, how would you rate this person's performance as a sales manager?" Participants responded using a 7-point Likert scale ranging from "Very poor performance" to "Very high performance." The internal consistency reliability estimate was adequate $(a=.93)$.

Manipulation Check. To ensure that participants correctly perceived the performance trend manipulation, I included a single item to serve as a manipulation check: "How would you describe the performance of the sales manager you just rated?" Participants were to select one of the following three response options: "Performance declined over time," "performance increased over time," or "performance did not change over time."

To ensure that participants correctly perceived the dispositional cue manipulation, I included two items to serve as manipulation checks: "Based on the direct supervisor's comments, how would you rate this sales manager's ability?" and "Based on the direct supervisor's comments, how would you rate this sales manager's effort?" Response options for these two items were "High Ability (Effort)," "Low Ability (Effort)," and 
"Unsure." To assess the efficacy of the study manipulations, I performed a chi-square test on each manipulation check item (these analyses are discussed in greater detail below).

\section{Procedure}

I utilized a 3 (performance trend: positive vs. negative vs. flat) x 2 (cued ability: high vs. low) x 2 (cued effort: high vs. low) between-subjects factorial design. All data were collected through an online experiment management system (Qualtrics and SONA Systems). Participants were instructed to assume the role of a supervisor and to evaluate the performance of a hypothetical salesperson. After agreeing to consent, each participant read the following set of instructions:

We're interested in studying how people form impressions of another person's job performance and how a person's job performance influences how they are perceived by others. In this experiment, we ask that you take on the role of a manager who is conducting a performance appraisal. You will be rating the performance of Chris, a Sales Manager who has just completed his first year on the job. You will begin by reading a brief note about Chris from his direct supervisor. On the following page, you will find a graph depicting Chris' sales performance over the past year. As a sales manager, Chris' performance is measured by sales volume. Sales volume refers to the total dollar value of products sold in a given period of time. After reviewing the graph, we will ask that you answer some questions about it, followed by some questions about how you would rate Chris' job performance and some questions about how you would rate Chris in terms of his general attributes. Finally, we will ask you some 
questions about yourself.

Participants were randomly assigned to one of twelve conditions (see Appendix D). As indicated above, participants were first exposed to the sales performance profile and the dispositional cue manipulation. Then participants responded to the MOAPS, demographic items (placed here to serve as a distractor task), and rated the sales manager's job performance. Finally, participants responded to the manipulation check items.

\section{Analyses}

To assess the efficacy of the manipulations, I conducted a chi-square test on the manipulation check items. A significant chi-square suggests that, overall, participants perceived the manipulations as intended. To test the main effect and interaction hypotheses, I used fixed effects analysis of variance methods (MANOVA and ANOVA). To test the mediation and conditional indirect effects hypotheses, I specified a conditional process model as outlined by Hayes (2012) and Hayes and Preacher (2012).

\section{Results}

To assess perceptions of the trend manipulation, I performed a chi-square test on the manipulation check item. The results suggested that participants correctly perceived the trend manipulation $\left[\chi^{2}(4)=530.40, p<.05\right]$. Specifically, $84.4 \%$ of participants in the negative trend condition, $77.7 \%$ of participants in the flat trend condition, and $79.4 \%$ of participants in the positive trend condition perceived the manipulation check as intended. To assess perceptions of the ability cue manipulation, I conducted a chi-square test on the manipulation check item. The results suggested that participants correctly perceived the manipulation $\left[\chi^{2}(2)=81.97, p<.05\right]$. In the low ability condition, $54 \%$ of 
participants perceived the manipulation as intended, while $32.6 \%$ indicated "unsure" and $14.6 \%$ indicated "high ability." In the high ability condition, $46.4 \%$ of participants perceived the manipulation as intended, while $33.5 \%$ of participants indicated "unsure" and $20.2 \%$ of participants indicated "low ability." Finally, to assess perceptions of the effort cue manipulation, I conducted a chi-square test on the manipulation check item. The results suggested that participants correctly perceived the manipulation $\left[\chi^{2}(2)=\right.$ $88.05, p<.05]$. In the low effort condition, $60.2 \%$ of participants perceived the manipulation as intended, while $27.5 \%$ indicated "unsure" and $12.3 \%$ indicated "high effort." In the high effort condition, $45.9 \%$ of participants perceived the manipulation as intended, while $28.4 \%$ indicated "unsure" and $25.7 \%$ indicated "low effort." The pattern of results observed suggests that across study manipulations, participants generally perceived the manipulations as they were intended to. On the basis of the results of the chi-square tests, I include all participants in subsequent analyses. Furthermore, when screening out participants who failed either the cued ability or cued effort manipulation checks, my cell counts dropped to an unreasonably low level (i.e., $\sim 15$ per cell). Nonetheless, I re-ran all of the analyses for this subset of the sample and only minor differences were observed. I note the instances where the findings were discrepant from what I observed when including the entire sample in the analyses.

Means and standard deviations for study variables by condition are depicted in Table 2. Means, standard deviations, and intercorrelations among study variables are depicted in Tables 3-5, for the positive trend condition, flat trend condition, and negative trend condition, respectively. Hypotheses 1-3 predicted a main effect of performance trend on performance ratings, ability attributions, and effort attributions, respectively. As 
a preliminary test of these hypotheses, I specified a fixed effect MANOVA in which performance trend (i.e., positive, flat, negative) was the independent variable and performance ratings, ability attributions, and effort attributions were the dependent variables. The results of this model suggested a significant multivariate main effect of performance trend $\left[\lambda_{\text {Wilks }}=.73, \mathrm{~F}(6,1042)=29.66, p<.05 ; \eta_{\text {partial }}^{2}=.15\right]$ on the linear combination of these three dependent variables. To better understand these effects, I specified a series of one-way ANOVA models. Each model is discussed below in relation to the specific hypothesis being tested.

Table 2

Descriptive statistics for study variables by condition

\begin{tabular}{lcccccccccccc}
\hline & Pos & Neg & Flat & Pos & Neg & Flat & Pos & Neg & Flat & Pos & Neg & Flat \\
& HA/HE & HA/HE & HA/HE & HA/LE & HA/LE & HA/LE & LA/HE & LA/HE & LA/HE & LA/LE & LA/LE & LA/LE \\
\hline $\mathrm{N}$ & 47 & 45 & 41 & 45 & 44 & 42 & 41 & 45 & 39 & 47 & 47 & 44 \\
MOAPS A & 5.86 & 3.92 & 4.85 & 5.01 & 4.11 & 4.36 & 4.69 & 4.35 & 4.31 & 4.80 & 3.71 & 4.25 \\
& $(.96)$ & $(1.32)$ & $(1.16)$ & $(1.32)$ & $(1.25)$ & $(1.41)$ & $(1.26)$ & $(1.12)$ & $(.97)$ & $(1.21)$ & $(1.22)$ & $(1.28)$ \\
& 6.14 & 4.20 & 5.17 & 5.18 & 5.08 & 5.12 & 5.57 & 4.50 & 4.53 & 4.77 & 4.71 & 4.87 \\
MOAPS E & $(.89)$ & $(1.16)$ & $(1.14)$ & $(1.27)$ & $(.94)$ & $(.95)$ & $(.98)$ & $(1.4)$ & $(1.00)$ & $(1.17)$ & $(1.13)$ & $(1.16)$ \\
& 5.86 & 3.10 & 4.24 & 4.60 & 2.73 & 3.67 & 4.18 & 2.54 & 3.33 & 3.87 & 2.42 & 3.12 \\
\multirow{2}{*}{ Rating } & $(1.22)$ & $(1.42)$ & $(1.40)$ & $(1.57)$ & $(1.13)$ & $(1.09)$ & $(1.69)$ & $(1.45)$ & $(1.04)$ & $(1.25)$ & $(1.16)$ & $(1.26)$
\end{tabular}

Note. Means appear in cells with standard deviations in parentheses. Pos = positive trend condition, Neg = negative trend condition, Flat $=$ flat trend condition, $\mathrm{HA}=$ high cued ability condition, $\mathrm{LA}=$ low cued ability condition, $\mathrm{HE}=$ high cued effort condition, $\mathrm{LE}=$ low cued effort condition, MOAPS A = multidimensional observer attribution for performance ability subscale, MOAPS $\mathrm{E}=$ multidimensional observer attribution for performance effort subscale, Rating $=$ job performance rating. 
Table 3

Means, standard deviations, and intercorrelations among study variables (positive trend condition)

\begin{tabular}{llcccccccc}
\hline & Mean & $95 \%$ CIs & SD & 1 & 2 & 3 & 4 & 5 \\
\hline 1 & Ability Cue $^{\mathrm{a}}$ & .51 & -- & .50 & -- & & & & \\
2 & Effort Cue $^{\mathrm{a}}$ & .49 & -- & .50 & .05 & -- & & & \\
3 & MOAPS Ability & 5.11 & $4.9,5.3$ & 1.27 & $.28^{*}$ & $.16^{*}$ & $(.93)$ & & \\
4 & MOAPS Effort & 5.41 & $5.2,5.6$ & 1.20 & $.22^{*}$ & $.38^{*}$ & $.64^{*}$ & $(.91)$ & \\
5 & Performance Rating & 4.64 & $4.4,4.9$ & 1.62 & $.38^{*}$ & $.26^{*}$ & $.45^{*}$ & $.43^{*}$ & $(.96)$
\end{tabular}

Note. $N=180 .{ }^{\mathrm{a}} 0=$ low, $1=$ high. ${ }^{*}$ significant at $p<.05$. Lower and upper $95 \%$ confidence intervals appear in brackets. $95 \% \mathrm{CI}=$ lower and upper $95 \%$ confidence intervals around the mean. Coefficient alpha reliability estimates appear in the diagonal.

\section{Table 4}

Means, standard deviations, and intercorrelations among study variables (flat trend condition)

\begin{tabular}{llcccccccc}
\hline & & Mean & $95 \%$ CIs & SD & 1 & 2 & 3 & 4 & 5 \\
\hline 1 & Ability Cue $^{\mathrm{a}}$ & .50 & -- & .50 & -- & & & & \\
2 & Effort Cue $^{\mathrm{a}}$ & .48 & -- & .50 & .02 & -- & & & \\
3 & MOAPS Ability & 4.44 & $4.3,4.6$ & 1.23 & .13 & .12 & $(.89)$ & & \\
4 & MOAPS Effort & 4.93 & $4.8,5.1$ & 1.09 & $.20^{*}$ & -.06 & $.50 *$ & $(.83)$ & \\
5 & Job Performance & 3.59 & $3.4,3.8$ & 1.27 & $.29 *$ & $.16^{*}$ & $.20^{*}$ & $.22^{*}$ & $(.95)$
\end{tabular}

Note. $N=166 .{ }^{\mathrm{a}} 0=$ low, $1=$ high. ${ }^{*}$ significant at $p<.05 .95 \% \mathrm{CI}=$ lower and upper $95 \%$ confidence intervals around the mean. Coefficient alpha reliability estimates appear in the diagonal. 
Table 5

Means, standard deviations, and intercorrelations among study variables (negative trend condition)

\begin{tabular}{llcccccccc}
\hline & & Mean & $95 \%$ CIs & SD & 1 & 2 & 3 & 4 & 5 \\
\hline 1 & Ability Cue $^{\mathrm{a}}$ & .49 & -- & .50 & -- & & & & \\
2 & Effort Cue $^{\mathrm{a}}$ & .49 & -- & .50 & .02 & -- & & & \\
3 & MOAPS Ability & 4.01 & $3.8,4.2$ & 1.24 & 0.00 & .09 & $(.86)$ & & \\
4 & MOAPS Effort & 4.62 & $4.4,4.8$ & 1.20 & .01 & $-.22 *$ & $.52 *$ & $(.81)$ & \\
5 & Performance Rating & 2.70 & $2.5,2.9$ & 1.31 & $.17 *$ & .10 & .15 & .04 & $(.94)$
\end{tabular}

Note. $N=180 .{ }^{a} 0=$ low, $1=$ high. ${ }^{*}$ significant at $p<.05 .95 \% \mathrm{CI}=$ lower and upper $95 \%$ confidence intervals around the mean. Coefficient alpha reliability estimates appear in the diagonal.

Hypothesis 1 predicted a main effect of performance trend on performance ratings, such that performance ratings would be highest in the positive performance trend condition, followed by the flat performance trend condition, and finally, the negative performance trend condition. To test this hypothesis, I specified a one-way ANOVA model in which performance trend was the independent variable and performance rating was the dependent variable. Furthermore, I specified the following planned contrasts: positive trend condition vs. flat and negative trend conditions, negative trend condition vs. flat and positive trend conditions, negative trend condition vs. positive trend condition, negative trend condition vs. flat trend condition, and flat trend condition vs. positive trend condition. The results of this ANOVA model indicated significant mean differences in performance ratings between the three trend conditions $\left[F(2)=85.37, p<.05, \eta^{2}\right.$ partial $=.25]$. The results of the planned contrasts are depicted in Table 6 and fully support hypothesis 1 -- mean performance ratings associated with each condition are significantly 
different from one another, with positive trends being associated with the highest ratings, followed by flat trends, and finally, negative trends. The effect is depicted graphically in Figure 3.

Table 6

Planned contrasts for ANOVA model comparing differences in performance ratings across trend conditions

\begin{tabular}{lccc}
\hline Contrast & Value & SE & $\mathrm{t}$ \\
\hline Positive vs. flat and negative & 3.00 & .26 & $11.53^{*}$ \\
Negative vs. flat and positive & 2.84 & .26 & $10.92^{*}$ \\
Negative vs. positive & 1.94 & .15 & $13.05^{*}$ \\
Negative vs. flat & .89 & .15 & $5.87^{*}$ \\
Flat vs. positive & 1.05 & .15 & $6.92^{*}$
\end{tabular}

Note. $N=526 .{ }^{*}$ significant at $p<.05 . \mathrm{DF}=523$.

Figure 3

Main effect of performance trend on performance ratings

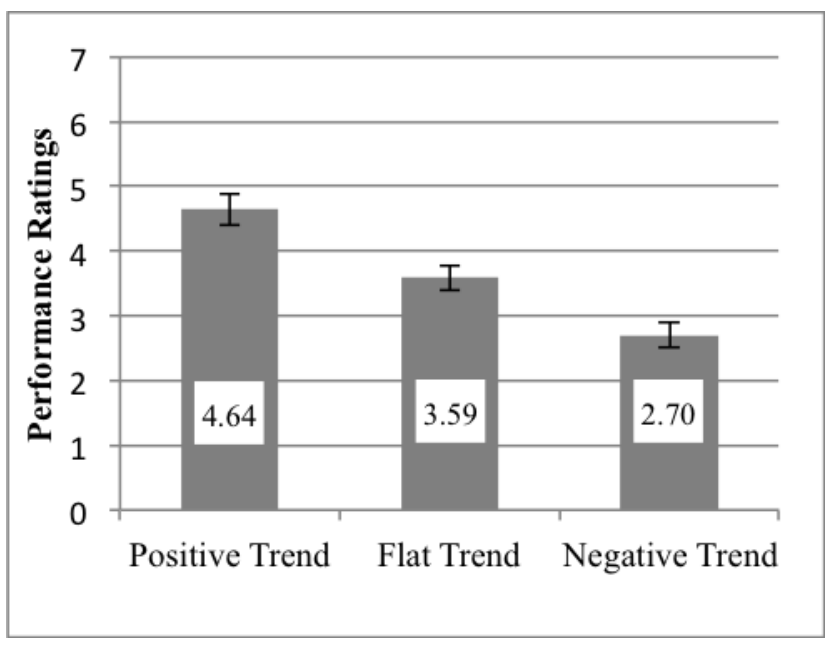

Note. $N=526$. Means are noted within each bar. Error bars indicate $95 \%$ confidence intervals. 
Hypothesis 2 predicted a main effect of performance trend on ability attributions, such that ability attributions would be highest in the positive performance trend condition, followed by the flat performance trend condition, and finally, the negative performance trend condition. To test this hypothesis, I specified a one-way ANOVA model in which performance trend was the independent variable and ability attributions was the dependent variable. Furthermore, I specified the same planned contrasts as hypothesis 1. The results of this ANOVA model indicated significant mean differences in ability attributions between the three trend conditions $\left[F(2)=34.86, p<.05, \eta_{\text {partial }}^{2}=.12\right]$. The results of the planned contrasts are depicted in Table 7 and fully support hypothesis 2 -mean ability attributions associated with each condition are significantly different from one another, with positive trends being associated with the highest ability attributions, followed by flat trends, and finally, negative trends. The effect is depicted graphically in Figure 4.

Table 7

Planned contrasts for ANOVA model comparing differences in ability attributions across trend conditions

\begin{tabular}{lccc}
\hline Contrast & Value & SE & $\mathrm{t}$ \\
\hline Positive vs. flat and negative & 1.76 & .23 & $7.65^{*}$ \\
Negative vs. flat and positive & 1.51 & .23 & $6.60^{*}$ \\
Negative vs. positive & 1.09 & .13 & $8.29^{*}$ \\
Negative vs. flat & .42 & .13 & $3.16^{*}$ \\
Flat vs. positive & .67 & .13 & $4.96^{*}$ \\
Note. $N=526$. *significant at $p<.05 . \mathrm{DF}=523$. & &
\end{tabular}


Figure 4

Main effect of performance trend on ability attributions

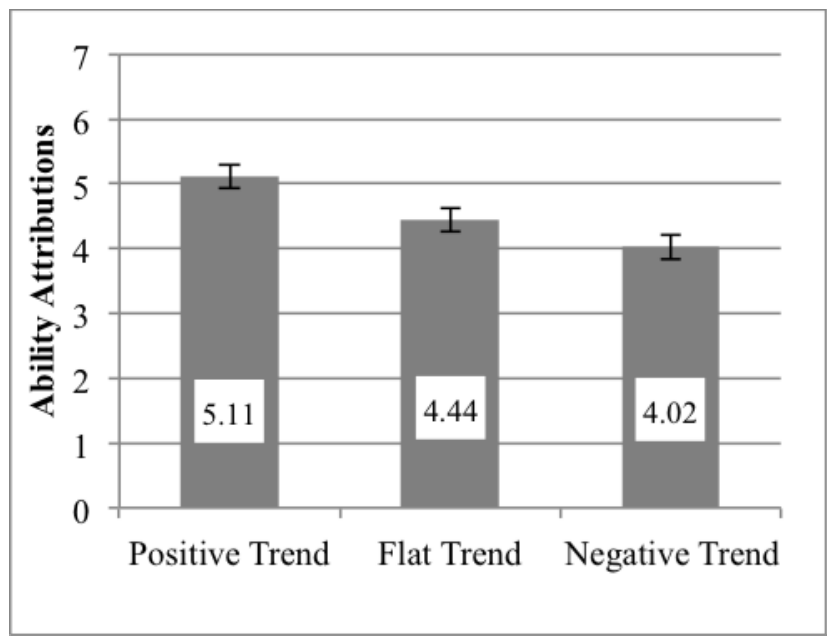

Note. $N=526$. Means are noted within each bar. Error bars indicate $95 \%$ confidence intervals.

Hypothesis 3 predicted a main effect of performance trend on effort attributions, such that effort attributions would be highest in the positive performance trend condition, followed by the flat performance trend condition, and finally, the negative performance trend condition. To test this hypothesis, I specified a one-way ANOVA model in which performance trend was the independent variable and effort attributions was the dependent variable. Furthermore, I specified the same planned contrasts as hypotheses 1 and 2 . The results of this ANOVA model indicated significant mean differences in effort attributions between the three trend conditions $\left[F(2)=21.11, p<.05, \eta_{\text {partial }}^{2}=.08\right]$. The results of the planned contrasts are depicted in Table 8 and are consistent with hypothesis 3 -- mean effort attributions associated with each condition are significantly different from one another, with positive trends being associated with the highest effort attributions, followed by flat trends, and finally, negative trends. The effect is depicted graphically in Figure 5. 
Table 8

Planned contrasts for ANOVA model comparing differences in effort attributions across trend conditions

\begin{tabular}{lccc}
\hline Contrast & Value & SE & $\mathrm{t}$ \\
\hline Positive vs. flat and negative & 1.28 & .21 & $5.96^{*}$ \\
Negative vs. flat and positive & 1.10 & .21 & $5.13^{*}$ \\
Negative vs. positive & .79 & .12 & $6.44^{*}$ \\
Negative vs. flat & .31 & .13 & $2.46^{*}$ \\
Flat vs. positive & .48 & .13 & $3.86^{*}$ \\
& & & \\
\hline
\end{tabular}

Note. $N=526 .{ }^{*}$ significant at $p<.05 . \mathrm{DF}=523$.

Figure 5

\section{Main effect of performance trend on effort attributions}

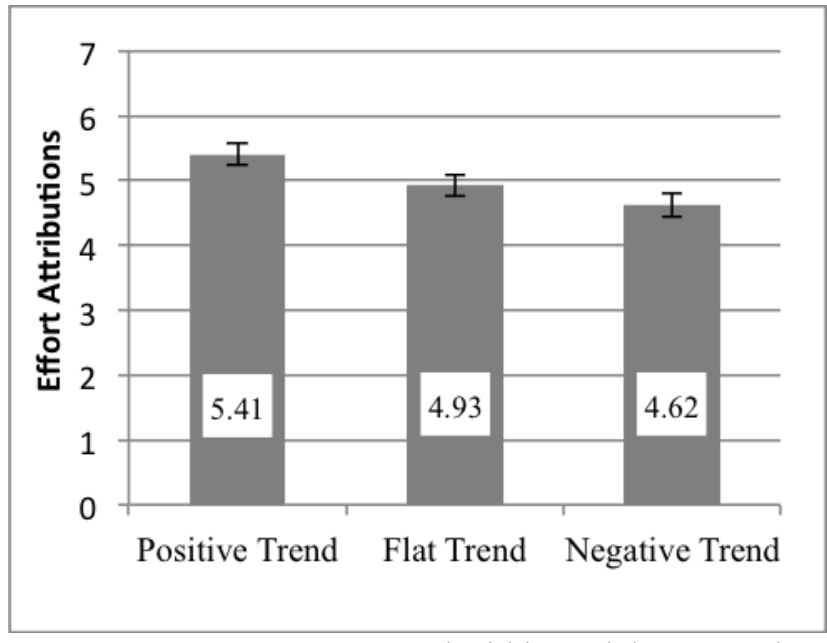

Note. $N=526$. Means are noted within each bar. Error bars indicate $95 \%$ confidence intervals.

Hypotheses 4 and 5 predicted that ability attributions and effort attributions, respectively, account for variance in performance ratings incremental to one another and performance trend. Hypotheses 6 and 7 predicted that ability attributions and effort attributions, respectively, mediate the relationship between performance trend and 
performance ratings. In testing these hypotheses, I consider only the positive vs. negative trend conditions, and exclude the flat trend condition from analyses. I proceeded in this manner for several reasons. First, the primary intention of the present study is to examine the manner in which dynamic job performance is assessed. As job performance is not dynamic in the flat trend condition, modeling this condition into subsequent analyses is not theoretically meaningful. Furthermore, the results of the prior ANOVA models suggest that all outcomes of interest differed significantly across experimental (i.e., positive trend, negative trend) and control (i.e., flat trend) conditions. Thus, as my experimental manipulations had achieved their intended effects, consideration of the control condition in these analyses is not necessary.

In order to test hypotheses 4-7, I specified a single multiple-mediator indirect effect model (see Figure 6). The model is akin to computing the following regression models simultaneously: (1) job performance ratings regressed onto performance trend, ability attributions, and effort attributions, (2) ability attributions regressed onto performance trend, and (3) effort attributions regressed onto performance trend. The model accounted for $36 \%$ of the variance in performance ratings. The results indicated that, when accounting for the influence of effort attributions and performance trend, ability attributions significantly influenced performance ratings $(\beta=.23, p<.05)$. Thus, hypothesis 4 was supported. Furthermore, the results indicated that, when accounting for the influence of ability attributions and performance trend, effort attributions did not significantly influence performance ratings $(\beta=.10, p>.05)$. Thus, hypothesis 5 was not supported. However, when screening out participants who failed the dispositional cue manipulation checks, the path from effort attributions to performance ratings, controlling 
for performance trend and ability attributions, did reach conventional levels of statistical significance $(\beta=.25, p<.05)$.

Figure 6

Results of multiple mediator indirect effects model

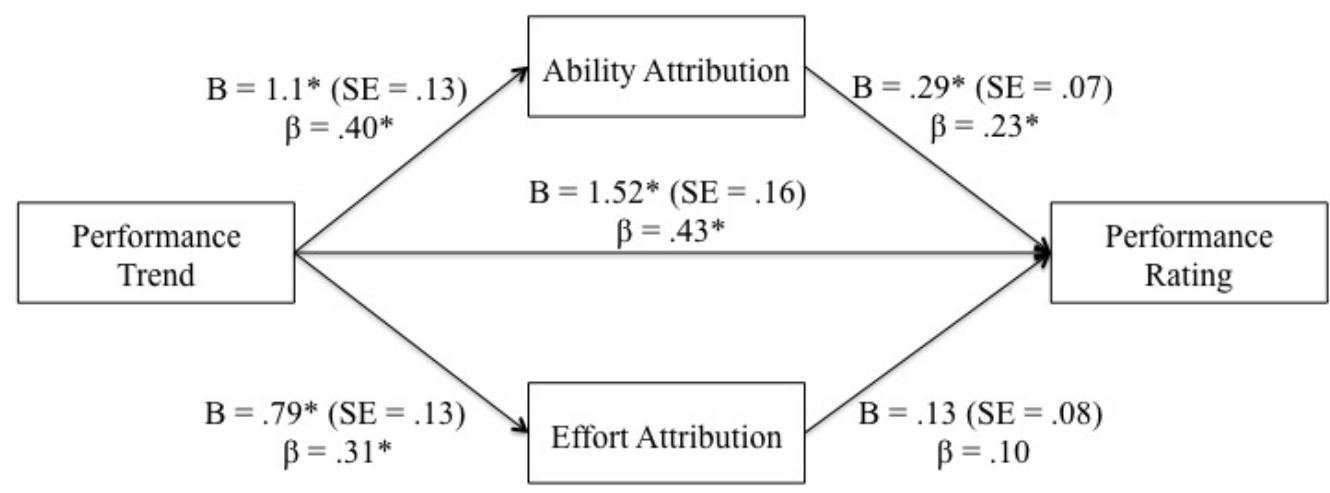

Note. $N=360$. *significant at $p<.05$. Performance trend is coded as $0=$ negative and $1=$ positive.

Hypotheses 6 and 7 specified an indirect effects (i.e., mediation) model, whereby the effect of performance trend on performance ratings is transmitted through attributions to ability and effort, respectively. As can be seen in Figure 6, the path from performance trend to ability attributions is statistically significant, as well as the path from ability attributions to performance ratings, controlling for performance trend and effort attributions, which suggests that mediation is occurring and provides partial support for hypothesis 6 -- that the relationship between performance trend and performance rating is mediated by ability attributions (MacKinnon, Lockwood, Hoffman, West, \& Sheets, 2002). Furthermore, while the path from performance trend to effort attributions is statistically significant, the path from effort attributions to performance ratings, controlling for ability attributions and performance trend, is not statistically significant. Therefore, I cannot conclude that effort attributions mediated the relationship between performance trend and performance ratings, and thus, hypothesis 7 was not supported. 
To more formally assess the statistical significance of the indirect effects proposed here, and as recommended by recent scholarship (e.g., MacKinnon, Lockwood, \& Williams, 2004), I computed bootstrapped and bias-corrected 95\% confidence intervals around the estimates for the indirect effects based on 2000 bootstrapped samples (Preacher \& Hayes, 2008; Shrout and Bolger, 2002). I conducted these analyses using an SPSS bootstrapping macro developed by Preacher and Hayes (2004). The bootstrapped indirect effect (IE) of performance trend on performance ratings through ability attributions was statistically significant $(\mathrm{IE}=.32, \mathrm{SE}=.10, p<.05,95 \% \mathrm{CI}: \mathrm{L}=.12$; $\mathrm{U}=.52$ ), while the bootstrapped IE of performance trend on performance ratings through effort attributions was not $(\mathrm{IE}=.11, \mathrm{SE}=.07, p>.05,95 \% \mathrm{CI}: \mathrm{L}=-.02 ; \mathrm{U}=.25)$. These analyses provided support for hypothesis 6, but failed to support hypothesis 7 .

Hypotheses 8-12 predicted main effects and interactions between the cued ability and cued effort manipulations on performance ratings, ability attributions, and effort attributions. As a preliminary test of these hypotheses, I specified a 2 (ability cue: low vs. high) x 2 (effort cue: low vs. high) fixed effects MANOVA in which ability attributions, effort attributions, and subjective performance ratings were dependent variables. The model suggested a significant multivariate main effect of cued ability $\left[\lambda_{\text {Wilks }}=.93, F(3\right.$, $\left.520)=12,76, p<.05 ; \eta_{\text {partial }}^{2}=.07\right]$ and cued effort $\left[\lambda_{\text {Wilks }}=.97, \mathrm{~F}(3,520)=5.40, p\right.$ $\left.<.05 ; \eta_{\text {partial }}^{2}=.03\right]$ on the linear combination of these three dependent variables. However, the two-way cued ability by cued effort interaction on the linear combination of the dependent variables was not statistically significant $\left[\lambda_{\text {Wilks }}=.99, \mathrm{~F}(3,520)=1.78\right.$, $\left.p>.05 . ; \eta_{\text {partial }}^{2}=.01\right]$. 
To better understand these multivariate effects, I specified a 2 (ability cue: low vs. high) x 2 (effort cue: low vs. high) between-subjects ANOVA model for each dependent variable (i.e., performance judgments, ability attributions, effort attribution). Hypothesis 8 predicted a main effect of cued ability on performance ratings. Results of the ANOVA model supported this hypothesis $\left[\mathrm{H} 8: \mathrm{F}(1)=36.69, p<.05 . ; \eta_{\text {partial }}^{2}=.07\right]$. These results indicated that performance ratings were higher in the high ability condition $(\mathrm{M}=4.05)$ than in the low ability condition ( $M=3.23$; see Figure 7). Hypothesis 9 predicted a main effect of cued effort on performance ratings. Results of the ANOVA model supported this hypothesis $\left[\mathrm{H} 9: \mathrm{F}(1)=12.31, p<.05 . ; \eta_{\text {partial }}^{2}=.02\right]$. These results indicated that performance ratings were higher in the high effort condition $(\mathrm{M}=3.88)$ than in the low effort condition $(\mathrm{M}=3.41$; see Figure 7$)$. Hypothesis 10 predicted a cued ability by cued effort interaction such that the effect of cued ability on performance ratings would be stronger when cued effort was high. Results of the ANOVA model indicated a significant cued ability by cued effort interaction $\left[\mathrm{H} 10: \mathrm{F}(1)=4.26, p<.05 . ; \eta^{2}\right.$ partial $=.01]$. Consistent with hypothesis 10 , cued effort strengthened the effect of cued ability on performance ratings. Specifically, performance ratings were significantly higher when the employee was described as demonstrating high ability and high effort $(M=4.43)$ as opposed to high ability and low effort $(M=3.68)$. The effect is depicted graphically in Figure 8. When screening participants out based on the results of the manipulation check (as discussed earlier), the ability-by-effort interaction on performance ratings was not statistically significant $\left[\mathrm{F}(1)=2.08, p<.05 . ; \eta_{\text {partial }}^{2}=.01\right]$. 
Figure 7

Main effect of cued ability and cued effort on performance ratings

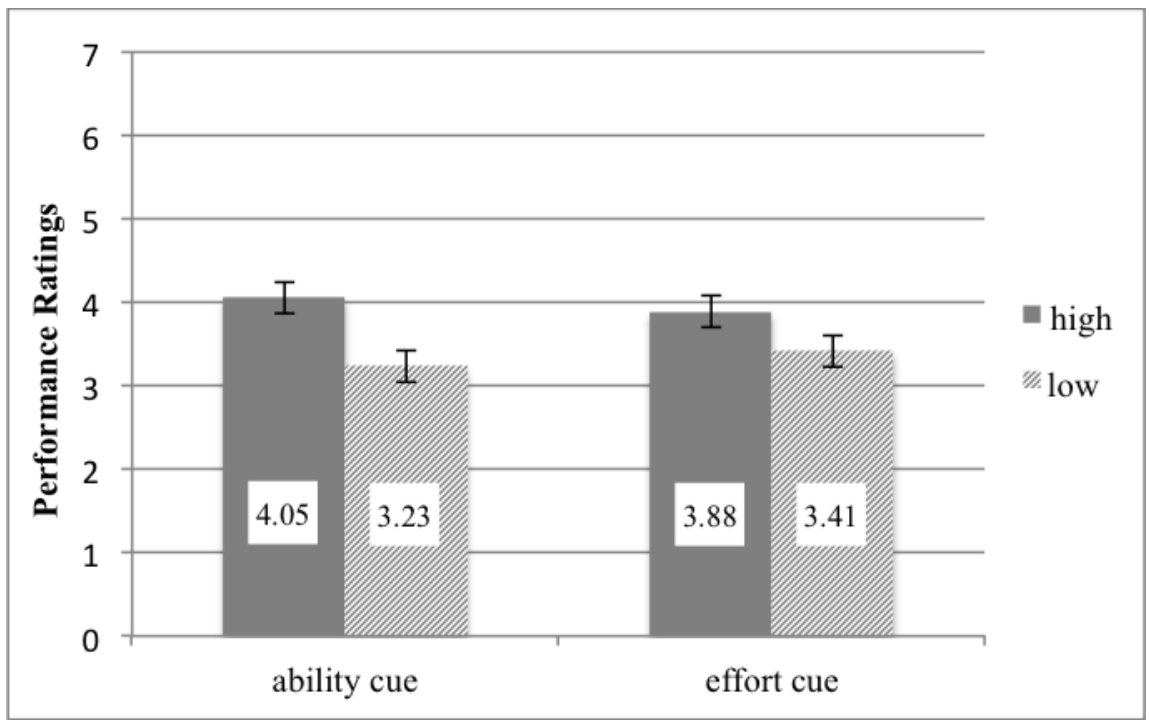

Note. $N=526$. Means are noted within each bar. Error bars indicate $95 \%$ confidence intervals.

Figure 8

Ability cue by effort cue interaction on performance ratings

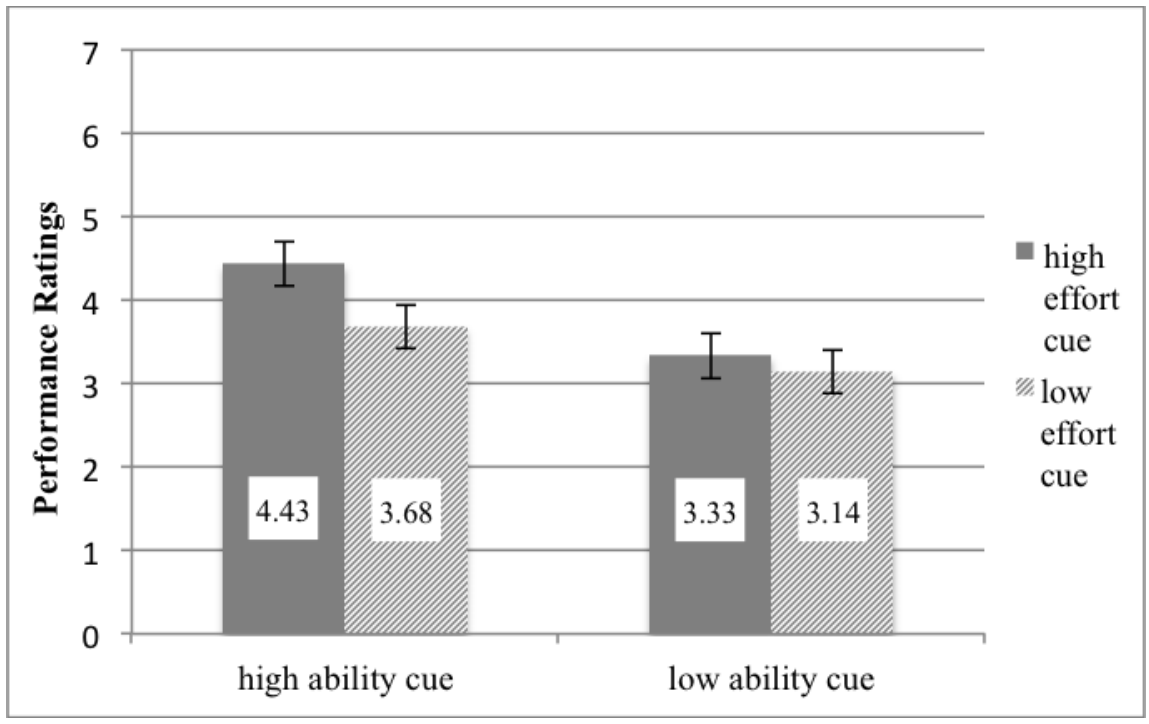

Note. $N=526$. Means are noted within each bar. Error bars indicate $95 \%$ confidence intervals.

Hypothesis 11 predicted a main effect of cued ability on ability attributions.

Furthermore, though I formed no hypotheses relating cued effort to ability attributions, I 
included the cued effort condition in the model to assess the presence of a main effect and interaction with cued ability. Therefore, I specified a 2 (ability cue: high vs. low) x 2 (effort cue: high vs. low) between-subjects ANOVA in which ability attributions was the dependent variable. In support of hypothesis 11, there was a significant main effect of cued ability on ability attributions $\left[\mathrm{H} 11: \mathrm{F}(1)=9.30, p<.05 . ; \eta^{2}\right.$ partial $\left.=.02\right]$. The nature of this effect is such that ability attributions were higher for participants who were in the high ability cue condition $(M=4.70)$ than for participants who were in the low ability cue condition ( $\mathrm{M}=4.35)$. Additionally, and though not hypothesized, there was a significant main effect of cued effort on ability attributions $\left[\mathrm{F}(1)=6.58, p<.05 ; \eta^{2}\right.$ partial $=.01]$, suggesting that ability attributions were higher for participants who were in the high cued effort condition $(M=4.67)$ than for participants who were in the low cued effort condition $(\mathrm{M}=4.38)$. These effects are depicted graphically in Figure 9. Finally, the cued ability by cued effort interaction was not significant $\left[\mathrm{F}(1)=.76, p>.05 ; \eta_{\text {partial }}^{2}\right.$ $=.001]$.

Figure 9

Main effect of ability cue and effort cue on ability attributions

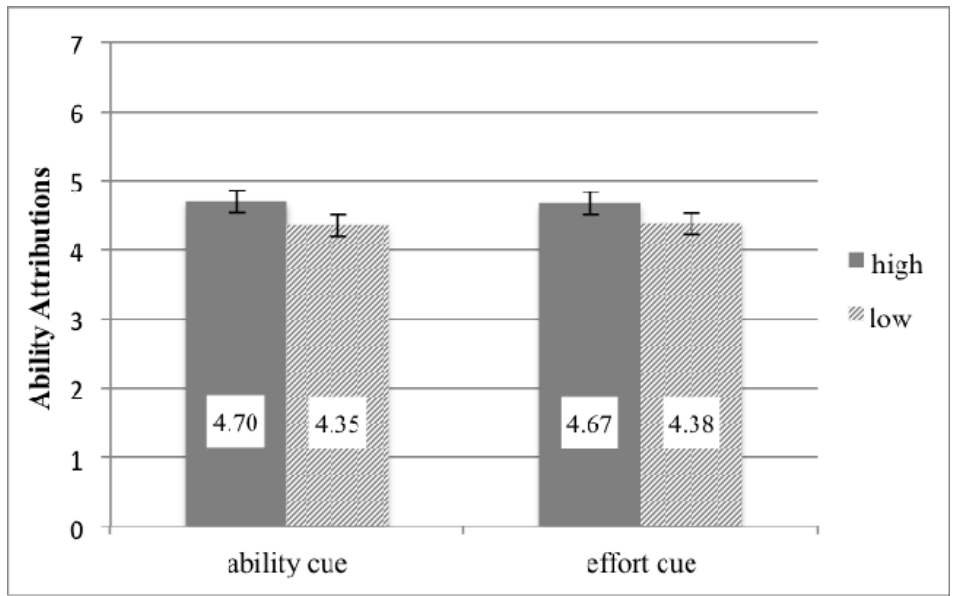

Note. $N=526$. Means are noted within each bar. Error bars indicate $95 \%$ confidence intervals. 
Hypothesis 12 predicted a main effect of cued effort on effort attributions.

Furthermore, though I formed no hypotheses relating cued ability to effort attributions, I included the cued ability condition in the model to assess the presence of a main effect and interaction with cued effort. Therefore, I specified a 2 (ability cue: high vs. low) x 2 (effort cue: high vs. low) between-subjects ANOVA in which effort attributions was the dependent variable. Counter to hypothesis 12 , I did not observe a significant main effect of cued effort on effort attributions $\left[\mathrm{H} 12: \mathrm{F}(1)=.44, \mathrm{p}>.05 . ; \eta^{2}\right.$ partial $\left.=.001\right]$. Thus, hypothesis 12 was not supported. These results suggest that effort attributions were not significantly different between participants in the high cued effort $(\mathrm{M}=5.02)$ and the low cued effort $(M=4.95)$ conditions. Though not hypothesized, there was a significant main effect of cued ability on effort attributions $\left[\mathrm{F}(1)=10.03, p<.05 ; \eta^{2}\right.$ partial $\left.=.02\right]$, suggesting that effort attributions were higher for participants who were in the high ability cue condition ( $M=5.15)$ as opposed to the low ability cue condition ( $M=4.82)$. These effects are depicted graphically in Figure 10. Finally, the cued ability by cued effort interaction on effort attributions was not statistically significant $[\mathrm{F}(1)=.01, p$ $\left.>.05 ; \eta_{\text {partial }}^{2}=.00\right]$. 
Figure 10

Main effect of ability cue and effort cue on effort attributions

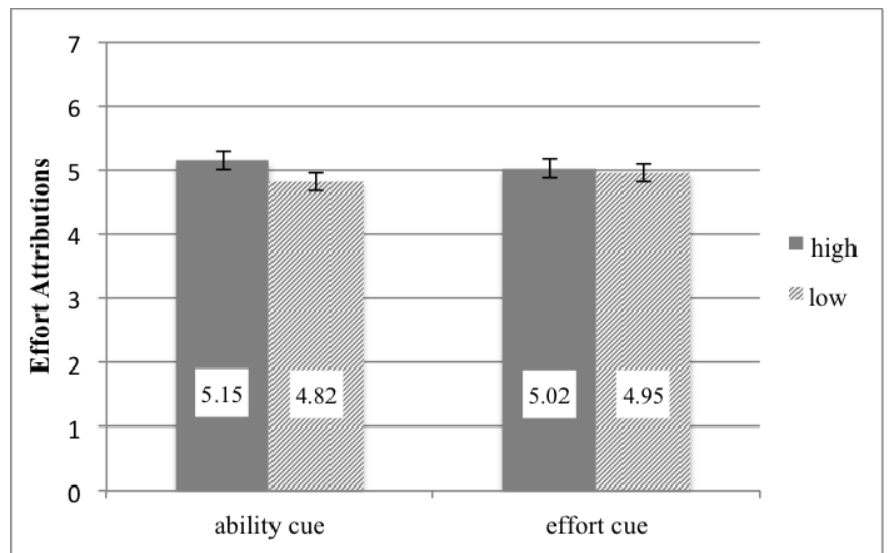

Note. $N=526$. Means are noted within each bar. Error bars indicate $95 \%$ confidence intervals.

Research questions 1-5 posed various two and three way interactions between (a) performance trend, (b) cued ability, and (c) cued effort on (a) ability attributions, (b) effort attributions, and (c) performance judgments. As a preliminary test of research questions 1-5, I specified a 3 (performance trend: positive versus flat versus negative) x 2 (cued ability: high versus low) x 2 (cued effort: high versus low) fixed effects MANOVA in which ability attributions, effort attributions, and subjective performance ratings were dependent variables. The model suggested a significant multivariate performance trend by cued ability interaction $\left[\lambda_{\text {Wilks }}=.97, \mathrm{~F}(6,1024)=2.31, p<.05 ; \eta_{\text {partial }}^{2}=.01\right]$, performance trend by cued effort interaction $\left[\lambda_{\text {Wilks }}=.91, \mathrm{~F}(6,1024)=8.54, p<.05\right.$; $\left.\eta_{\text {partial }}^{2}=.05\right]$, and performance trend by cued ability by cued effort interaction $\left[\lambda_{\text {wilks }}\right.$ $\left.=.97, \mathrm{~F}(6,1024)=2.55, p<.05 ; \eta_{\text {partial }}^{2}=.02\right]$ on the linear combination of these three dependent variables.

To better understand these multivariate effects, I specified a series of betweensubjects ANOVA models, discussed in detail below in relation to each research question. 
Research questions 1-3 posed the following interactions on performance ratings: (1) performance trend by cued ability, (2) performance trend by cued effort, and (3) performance trend by cued ability by cued effort, respectively. To address these research questions, I specified a 3 (performance trend: positive vs. flat vs. negative) x 2 (cued ability: high vs. low) x 2 (cued effort: high vs. low) between-subjects ANOVA in which performance ratings was the dependent variable.

Research question 1 posed a performance trend by cued ability interaction on performance ratings. The results of the between-subjects ANOVA indicated a significant performance trend by cued ability interaction on performance ratings [RQ1: $F(2)=3.85$, $p<.05 . ; \eta^{2}$ partial $\left.=.02\right]$. The nature of this effect is such that positive performance trends are rated more favorably when the employee is described as demonstrating high ability $(M=5.23)$ as opposed to low ability $(M=4.02$; see Figure 11). Research question 2 posed a performance trend by cued effort interaction on performance ratings. The results of the between-subjects ANOVA indicated that the performance trend by cued effort interaction was not statistically significant $\left[\mathrm{RQ} 2: \mathrm{F}(2)=2.05, p>.05 . ; \eta_{\text {partial }}^{2}=.01\right]$ (see Figure 12). Research question 3 posed a three-way performance trend by cued ability by cued effort interaction on performance ratings. The results of the between-subjects ANOVA indicated that this interaction was not statistically significant $[\mathrm{RQ} 3: \mathrm{F}(2)=.92$, $\left.p>.05 . ; \eta_{\text {partial }}^{2}=.004\right]$ (see Figure 13). 
Figure 11

Performance trend by ability cue interaction on performance ratings

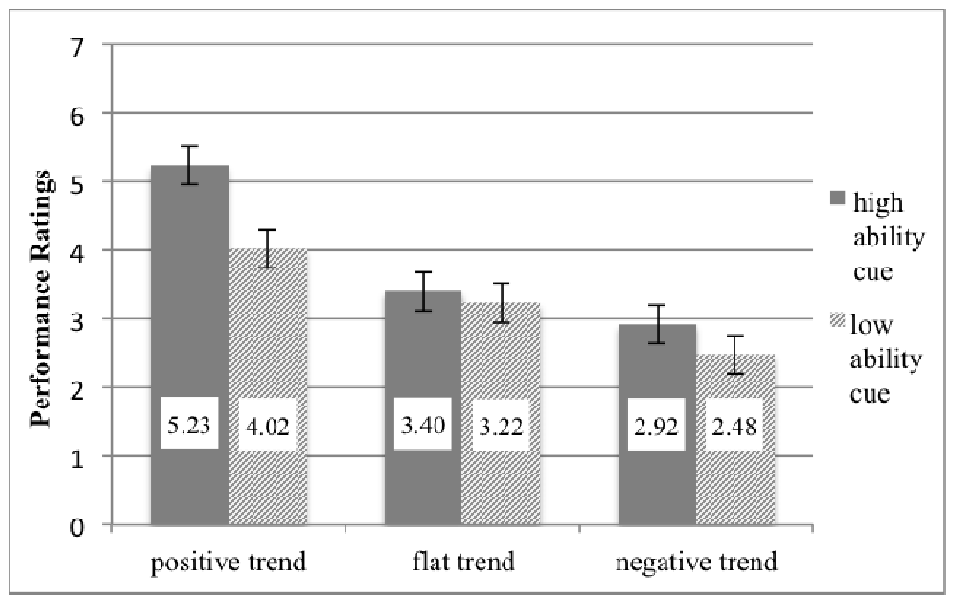

Note. $N=526$. Means are noted within each bar. Error bars indicate $95 \%$ confidence intervals.

Figure 12

Performance trend by effort cue interaction on performance ratings

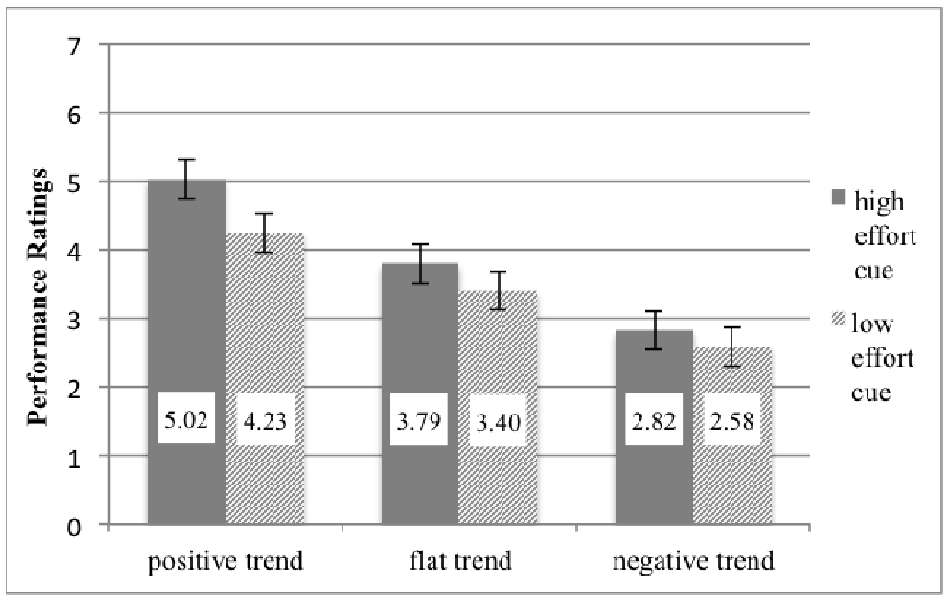

Note. $N=526$. Means are noted within each bar. Error bars indicate $95 \%$ confidence intervals. 
Figure 13

Performance trend by cued ability by cued effort interaction on performance ratings

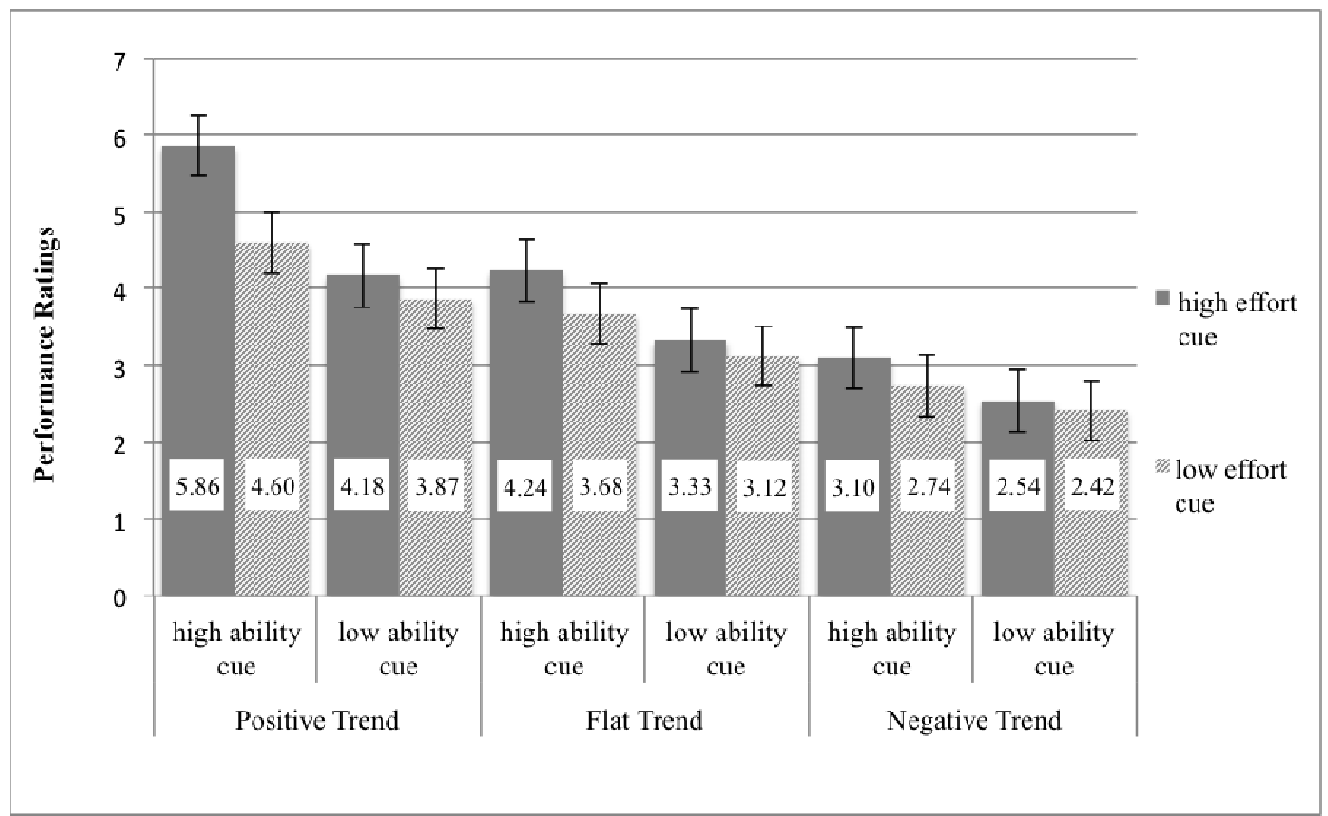

Note. $N=526$. Means are noted within each bar. Error bars indicate $95 \%$ confidence intervals.

Research question 4 posed a performance trend by cued ability interaction on ability attributions. To address this research question I specified a 3 (performance trend: positive vs. flat vs. negative) x 2 (cued ability: high vs. low) between-subjects ANOVA in which ability attributions was the dependent variable. The results indicated a significant performance trend by cued ability interaction on ability attributions [RQ4: $\left.\mathrm{F}(2)=3.64, p<.05 . ; \eta_{\text {partial }}^{2}=.01\right]$. The nature of this effect is such that positive performance trends were attributed to greater levels of ability when the employee is described as demonstrating high ability $(M=5.45)$ as opposed to low ability $(M=4.75)$. However, when performance trend was flat or negative, there was no difference between the high cued ability and low cued ability conditions. These effects are depicted graphically in Figure 14. 
Figure 14

Performance trend by ability cue interaction on ability attributions

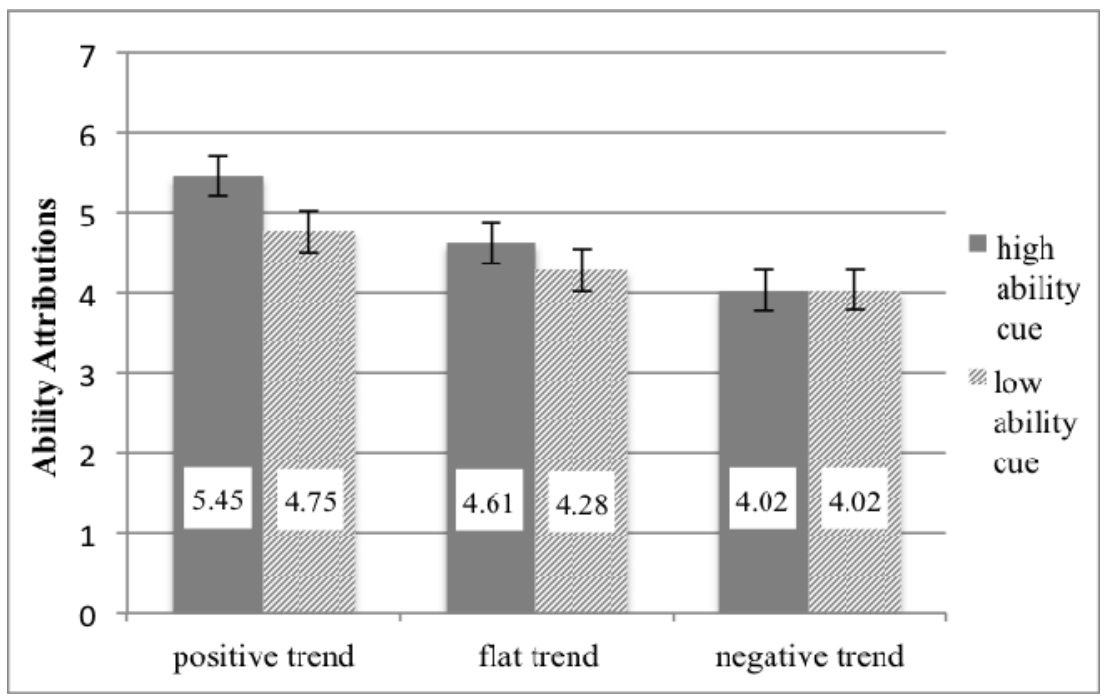

Note. $N=526$. Means are noted within each bar. Error bars indicate $95 \%$ confidence intervals.

Research question 5 posed a performance trend by cued effort interaction on

effort attributions. To address this research question, I specified a 3 (performance trend: positive vs. flat vs. negative) x 2 (cued effort: high vs. low) between-subjects ANOVA in which effort attributions was the dependent variable. The performance trend by cued effort interaction was statistically significant [RQ5: $\mathrm{F}(2)=19.50, p<.05$; $\left.\eta_{\text {partial }}^{2}=.07\right]$. The nature of this effect is such that high cued effort is associated with higher effort attributions only when performance trend is positive $(M=5.87$ vs. 4.97). Surprisingly, when performance trend is negative, the effect is reversed, such that high cued effort is associated with lower effort attributions than is low cued effort $(M=4.35$ vs. 4.88). The effect is depicted graphically in Figure 15. 
Figure 15

Performance trend by effort cue on effort attributions

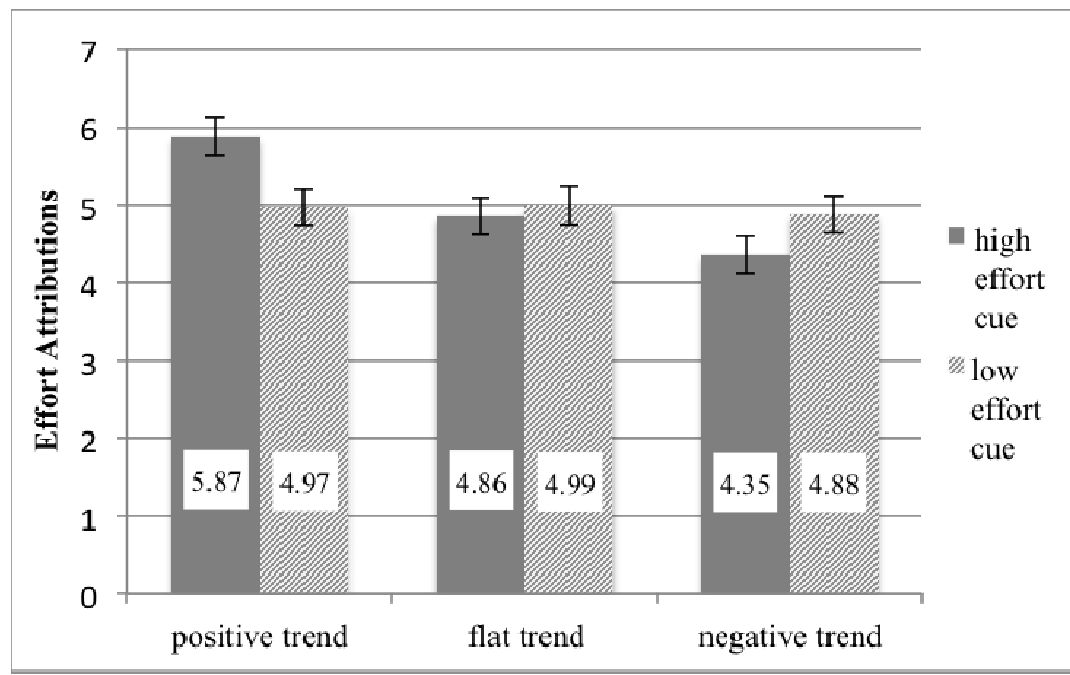

Note. $N=526$. Means are noted within each bar. Error bars indicate $95 \%$ confidence intervals.

Research question 6 posed that the indirect effect of performance trend on performance ratings through ability and effort attributions could be conditional upon cued ability and cued effort (i.e., the mediated effect is moderated by the dispositional cues). Consistent with the logic presented earlier, I consider only the experimental (i.e., positive and negative) trend conditions and exclude the control (i.e., flat) trend condition from these analyses. To address this research question, I specified a conditional process model using the Hayes (2012) PROCESS macro for SPSS. This model is similar to the mediation model tested earlier, but specifies direct and indirect effects that are conditional upon dispositional cues (see Figure 16). I assessed the statistical significance of the indirect effects at each level of the moderators by bootstrapping confidence intervals around each estimate of the indirect effect based on 2000 bootstrapped samples. The conditional indirect effects of ability attributions and effort attributions at the 
different levels of each moderator are depicted in Tables 9 and 10, respectively. In terms of ability attributions, the $95 \%$ confidence intervals associated with the indirect effect estimates at each level of each moderator overlap, suggesting that these estimates do not differ significantly from each other. These results suggest that the indirect effect of performance trend on performance ratings through ability attributions was not moderated by the dispositional cues. Nonetheless, the results indicated that when the employee was described as demonstrating low ability and high effort, the indirect effect of performance trend on performance ratings through ability attributions was not statistically significant. Specifically, the indirect effect through ability attributions was attenuated when the employee was described as demonstrating low ability and high effort. Thus, some evidence of moderated mediation was observed. When screening out participants who failed the dispositional cue manipulation checks, the indirect effect through ability was also not statistically significant when the employee was described as demonstrating low ability and low effort. In terms of effort attributions, the indirect effect estimates at each level of each moderator are all statistically nonsignificant. Thus, no evidence of moderated mediation was observed with respect to effort attributions. 
Figure 16

\section{Conditional indirect effects model}

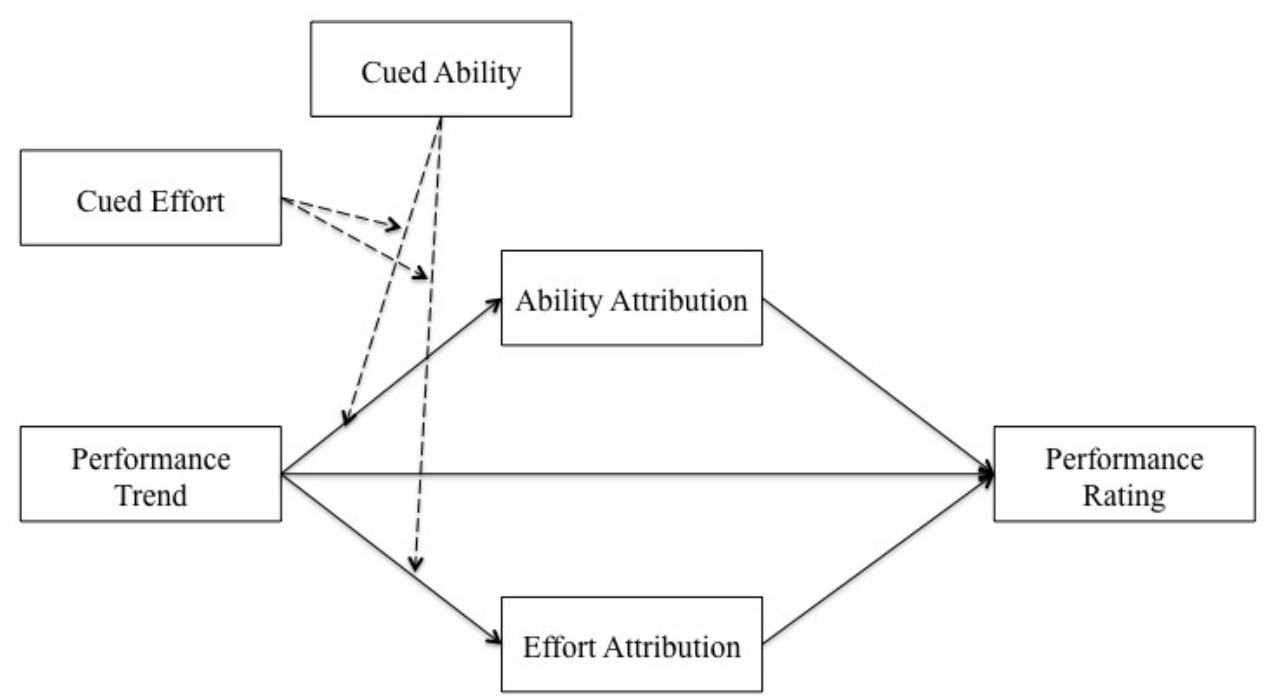

Note. Dashed lines indicate moderation.

\section{Table 9}

Conditional indirect effects of performance trend on performance ratings through ability attributions

\begin{tabular}{cccccc}
\hline Cued Ability & Cued Effort & IE & SE & $95 \% \mathrm{CI}_{\text {Lower }}$ & $95 \% \mathrm{CI}_{\text {Upper }}$ \\
\hline Low & Low & $.32^{*}$ & .12 & .13 & .61 \\
Low & High & .10 & .09 & -.04 & .33 \\
High & Low & $.26^{*}$ & .12 & .08 & .56 \\
High & High & $.57^{*}$ & .18 & .23 & .92
\end{tabular}

Note. $N=360$. *significant at $p<.05$. IE $=$ indirect effect. 
Table 10

Conditional indirect effects of performance trend on performance ratings through ability attributions

\begin{tabular}{cccccc}
\hline Cued Ability & Cued Effort & IE & SE & $95 \% \mathrm{CI}_{\text {Lower }}$ & $95 \% \mathrm{CI}_{\text {Upper }}$ \\
\hline Low & Low & .01 & .04 & -.05 & .11 \\
Low & High & .14 & .10 & -.02 & .38 \\
High & Low & .01 & .04 & -.04 & .13 \\
High & High & .26 & .17 & -.06 & .61 \\
\hline
\end{tabular}

Note. $N=360$. IE $=$ indirect effect.

\section{Discussion}

Researchers have discussed the importance of studying how raters make sense of dynamic performance and that attributions may be useful in this respect (Fisher, 2008; Reb \& Greguras, 2010). However, very few investigations have assessed this prospect empirically. Considering the support generated thus far for systematic trends in job performance across time (e.g., Hofmann et al., 1993; Ployhart \& Hakel, 1998), and the robust influence of performance trends on performance ratings (e.g., DeNisi \& Stevens, 1981; Reb \& Cropanzano, 2007), research into a dynamic performance appraisal process model is needed to advance performance management practice and theory. In the present study, I have addressed this gap by demonstrating empirical support for an attributional model of dynamic performance appraisal.

In support of hypotheses 1-3, (a) performance ratings, (b) ability attributions, and (c) effort attributions differed significantly across trend conditions. Specifically, each of these outcomes was lowest in the negative trend condition, followed by the flat trend 
condition, and highest in the positive trend condition. Furthermore, the mean level of performance depicted in each profile was identical, suggesting that the variation in performance trend alone can account for these effects. Hypothesis 4, which posed a positive relationship between ability attributions and performance ratings was supported, however, hypothesis 5 , which posed a positive relationship between effort attributions and performance ratings was not. Similarly, tests of hypotheses 6 and 7 indicated that ability attributions (hypothesis 6) but not effort attributions (hypothesis 7) mediated the relationship between performance trend and performance ratings. Taken together, these findings suggest the potency of ability attributions as perceived determinants of behavior, and as antecedents to performance judgments, as opposed to effort attributions.

The pattern of results may have been observed for several reasons. For instance, across experimental conditions, the performance trends unfolded in a fairly steady manner over a long period of time (i.e., one year). It seems reasonable that raters would perceive such a trajectory in job performance as stemming from internal and stable causes (i.e., ability; Weiner et al., 1972). Such stimuli may be unlikely to influence effort attributions, as effort is considered an internal and unstable cause of performance. Perhaps, in order to influence effort attributions, the dynamic performance profile would have to include a greater amount of variability. Furthermore, prior research had demonstrated an association between performance trend and effort attributions, but the performance profiles displayed weekly performance across 26 weeks (Reb \& Greguras, 2010). It is possible that effort attributions, as unstable causes of performance, are more likely to be invoked when considering changes in job performance over shorter periods of time. 
In support of hypotheses 8-10, I observed significant main effects and interactions between cued ability and cued effort on performance ratings. Such findings are consistent with much prior research (e.g., Knowlton \& Mitchell, 1980; Weiner \& Kukla, 1970), suggesting that performance is rated higher when the ratee is described as possessing (a) high ability as opposed to low ability (hypothesis 8 ) and (b) high effort as opposed to low effort (hypothesis 9), incremental to objective performance levels. Furthermore, and also consistent with prior research (e.g., Anderson \& Butzin, 1974), the relationship between cued ability and performance ratings was strengthened when cued effort was high (hypothesis 10). In support of hypothesis 11, I observed a significant main effect of cued ability on ability attributions. However, hypothesis 12 , which predicted a main effect of cued effort on effort attributions, was not supported. Specifically, regardless of whether the employee was described as possessing high effort or low effort, effort attributions did not differ. In speculating why the effort cue manipulation did not influence effort attributions, I consider aspects of the manipulation. Specifically, as depicted in Appendix A, the dispositional cue manipulation included adjectives related to ability, followed by those related to effort. As a result, participants may have attended much more to the ability manipulation as opposed to the effort manipulation. Thus, order effects may help to explain why the ability cue had a surprising main effect on effort attributions. The ability portion of the cue may have dominated subsequent judgments, as it was presented prior to the effort portion of the cue manipulation.

Examination of the research questions posed in this study revealed several interesting findings. In relation to research question 1, I observed a significant 
performance trend by cued ability interaction on performance ratings, such that high cued ability positively influenced performance ratings only when performance trend was positive. In relation to research question 2 and 3, I failed to detect a performance trend by cued effort interaction (research question 2), or a performance trend by cued ability by cued effort interaction (research question 3) on performance ratings. Taken together, these findings suggest that, to an extent, the manner in which job performance unfolds over time influences how raters use cues related to ability, but not effort, to judge overall performance. Furthermore, these results may indicate that cued ability exerts its strongest effect when it is consistent with the performance trend. That is, both positive performance trends and high ability cues are generally associated with high performance ratings (e.g., Anderson \& Butzin, 1974; Reb \& Cropanzano, 2007), and the effect seems to be augmented when these favorable performance indices are both present.

In relation to research question 4 , the performance trend by cued ability interaction on ability attributions was statistically significant. Cued ability was only related to ability attributions when performance trend was positive. In all other conditions, cued ability had no effect. The trend by ability cue interaction may have occurred because the performance trend and ability cue were consistent with one another. Specifically, research indicates that positive performance trends are associated with attributions to ability (Reb \& Greguras, 2010), and the effect appears to be augmented when the ability cue is consistent with what is indicated by the trend. In relation to research question 5, I observed a significant performance trend by cued effort interaction. Similar to research question 4 , high cued effort was associated with higher effort attributions only when performance trend was positive, perhaps a result of consistency 
between the performance cues. However, the effect was reversed when performance trend was negative. That is, in the negative performance trend condition, high cued effort was associated with lower effort attributions than was low cued effort. The effect may have been observed because of the influence of this pattern of cues on external attributions. For instance, if an employee is described as demonstrating considerable effort, but their performance continues to decline across time, it could be that the only logical reason is that something external to the employee (e.g., economic conditions) is causing the decline (Kelley, 1972, 1973). On the other hand, when the employee is described as not putting forth effort, then raters may perceive the decline as being due to the employee's (lack of) effort.

Finally, research question 6 concerned the extent to which the indirect effect model tested earlier is conditional upon the dispositional cue manipulations. The results of this analysis indicated that, by and large, the dispositional cues did not influence the indirect effect of performance trend on performance ratings through ability attributions. However, this was not unequivocal, as the indirect effect through ability attributions was attenuated when the employee was described as possessing low ability but high effort. This combination of cues may influence the indirect effect because it discounts ability as a plausible cause of performance, while also directing the rater's attention to an unstable cause of performance -- effort. However, the dispositional cues did not moderate the indirect effect of performance trend on performance ratings through effort attributions. This pattern of results again speaks to the strength of internal-stable (i.e., ability) attributions as perceived determinants of performance and as antecedents to performance judgments, as opposed to internal-unstable (i.e., effort) attributions. 


\section{Implications}

The results of the present study bear several implications for performance management research and theory. First, many studies have examined the influence of objective indices of job performance on performance ratings. However, much of the research has conceptualized job performance using a static performance framework. That is, while the stimuli used in prior studies likely exhibited some form of variation in performance levels across episodes (whether systematic or unsystematic), such variation is treated as error when research only considers the influence of mean performance levels on performance ratings. The results of the current study indicate shortcomings associated with this approach, as I found that three performance profiles with identical means were rated significantly differently from one another as a result of the manner in which the performance unfolded over time. While research that has considered only static indices

of performance has contributed greatly to our knowledge of performance appraisal, given the influence of dynamic performance characteristics on performance ratings (DeNisi \& Stevens, 1981; Reb \& Cropanzano, 2007), future research should examine the effects of features such as performance trend on performance ratings, rather than treating such dynamic characteristics as error.

Second, while empirical findings have emerged indicating that dynamic performance characteristics, such as performance trend, influence performance ratings, there has been a lack of research into how such characteristics influence other judgmental outcomes (e.g., attributions) and the causal relationships among these variables (Reb \& Greguras, 2007, 2010). Put differently, research has paid minimal attention to the person perception processes that account for the relationship between dynamic features of 
performance and overall performance judgments (Fisher, 2008). Given the evidence suggesting that performance is in fact dynamic across time (e.g., Hofmann et al., 1993; Ployhart \& Hakel, 1998; Thoresen et al., 2004), it is imperative that research identifies these processes in order to advance theories of performance appraisal. In the present study, by explicating the role of attributions as part of this process, I have helped to address this gap.

Finally, many studies have considered how attribution-related cues influence ratings of job performance (e.g., Knowlton \& Mitchell, 1980; Weiner \& Kukla, 1970). However, this research has all been conducted under a static performance perspective, for example, where overall performance was described dichotomously as a success or failure. Given the dynamic nature of job performance, research is needed to examine the extent to which the manner in which job performance unfolds across time serves as a boundary condition for prior findings. In the present study, despite the performance means being equated across conditions, my results suggested that the influence of attributional cues on performance ratings were much more pronounced when performance was ascending over time. As performance is now generally recognized as being dynamic over time (Hofmann et al., 1993; Ployhart \& Hakel, 1998), studies that consider static indices of performance only may be misrepresenting these effects.

\section{Limitations and Future Directions}

As indicated earlier, the effect of cued ability on attributions and performance ratings was much stronger than the effect of cued effort on these dependent variables, and this may be due to the order in which these cues were presented (i.e., cued ability followed by cued effort). Future research can reverse the order in which these cues are 
presented in order to examine if the primacy of one versus the other influences the results. Alternatively, research can counterbalance the order in which these cues are presented in order to account for the influence of any order effects.

In the present study, and consistent with many theories of person perception (e.g., Weiner et al., 1972), I manipulated cues related only to ability and effort. However, research indicates that dynamics in job performance can occur as a result of external factors, such as variation in sales referrals provided by the organization (Stewart \& Nandkeolyar, 2006). Future research should examine the influence of manipulated external cues, rather than solely internal cues, on the process model of dynamic performance appraisal considered here. It is possible that such cues would attenuate the relationship between performance trend and performance ratings by attenuating the performance trend-ability attribution relationship. Future research should empirically address this possibility.

Furthermore, in the present study, I examine the relationship between retrospective evaluations of performance trends, attributions, and performance ratings. This is useful for examining how perceptual heuristics influence the person perception and performance appraisal process. However, in a naturalistic performance appraisal environment, raters have observed performance unfolding over time and I do not capture this process in the present study. Future research can address this in several ways. For example, future lab studies can present raters with a series of vignettes that either increase or decrease in performance across time. After each vignette, the researchers can collect attributions and performance ratings. This design would allow researchers to assess how attributions and performance ratings change as a function of changes in job 
performance across time. Future research should also examine the relationship between performance trend and performance ratings in field settings. For example, researchers could examine the relationship between trends in sales agent's objective performance across a fiscal year and the results of their annual performance appraisal. Such a study would have greater fidelity to the performance appraisal process.

While several studies have been conducted into the dynamic performance characteristics-performance rating relationship, few studies have considered the influence of individual differences on this relationship (cf. Lanz \& Rudolph, 2013; Reb, Ferris, Lian, \& Ang, 2013). Given the evidence observed in this and other studies for the role of attributions in the dynamic performance appraisal process (e.g., Reb \& Greguras, 2010), research should consider individual differences in attributional tendencies. For example, raters who are high in attributional complexity should be more likely to consider external causes of dynamic performance characteristics than raters who are low in this trait (Fletcher, Danilovics, Fernandez, Peterson, \& Reeder, 1986). As a result, attributional complexity may attenuate the performance trend-performance rating relationship. The same can be said for other attributional individual differences, such as social attribution style. Future research should address this gap by considering the role of such individual differences on the process model considered here.

\section{Conclusion}

Despite the accumulation of evidence suggesting that job performance changes across time, and that such changes can influence performance ratings, little attention has been given to the mechanisms by which dynamic job performance is judged. In the present study, I contribute to this literature by explicating the role that attributions play in 
this process. Specifically, my results suggest that performance trend influences performance ratings partly through ability attributions (i.e., performance trend is positively related to ability attributions, which are positively related to performance ratings). While more research is needed to more fully understand the processes by which dynamic performance is evaluated, this study represents a step towards a much-needed model of dynamic performance appraisal. 


\section{References}

Ackerman, P. L., \& Heggestad, E. D. (1997). Intelligence, personality, and interests: Evidence of overlapping traits. Psychological Bulletin, 121(2), 219-245.

Ajzen, I., \& Fishbein, M. (2005). The influence of attidudes on behavior. In D. Albarracin, B. T. Johnson, \& M. P. Zanna (Eds.), The handbook of attitudes (pp. 173-221). Mahawah, NJ: Erlbaum.

Anderson, N. H. (1965). Averaging versus adding as a stimulus-combination rule in impression formation. Journal of Personality and Social Psychology, 2, 1-9.

Anderson, N. H., \& Butzin, C. A. (1974). Performance = motivation x ability: An integration-theoretical analysis. Journal of Personality and Social Psychology, 30(5), 598-604.

Ariely, D. (1998). Combining experiences over time: The effects of duration, intensity changes and on-line measurements on retrospective pain evaluations. Journal of Behavioral Decision Making, 11(1), 19-45.

Ariely, D., \& Carmon, Z. (2000). Gestalt characteristics of experiences: The defining features of summarized events. Journal of Behavioral Decision Making, 13(2), 191-201.

Ashkanasy, N. M. (1989). Causal attribution and supervisors' response to subordinate performance: The Green and Mitchell model revisited. Journal of Applied Social Psychology, 19(4), 309-330

Ashkanasy, N. M. (1995). Supervisory attributions and evaluative judgments of subordinate performance: A further test of the Green and Mitchell model. In M. J. Martinko (Ed.), Attribution theory: An organizational perspective (pp. 211-228). Delray Beach, FL: St. Lucie Press.

Ashkanasy, N. M., \& Humphrey, R. H. (2011). Current emotion research in organizational behavior. Emotion Review, 3(2), 214-224.

Austin, J. T., Humphreys, L. G., \& Hulin, C. L. (1989). Another view of dynamic criteria: A critical reanalysis of Barrett, Caldwell, and Alexander. Personnel Psychology, 42, 583-596.

Austin, J. T., \& Villanova, P. (1992). The criterion problem: 1917-1992. Journal of Applied Psychology, 77, 836-874.

Baron, R. M., \& Kenny, D. A. (1986). The moderator, mediator variable distinction in social psychological research: Conceptual, strategic, and statistical considerations. Journal of 
Personality and Social Psychology, 51(6), 1173-1182.

Barone, M. J., \& DeCarlo, T. E. (2012). Performance trends and salesperson evaluations: The moderating roles of evaluation task, managerial risk propensity, and firm strategic orientation. Journal of Personal Selling and Sales Management, 32(2), 207-223.

Barrett, G. V., \& Alexander, R. A. (1989). Rejoinder to Austin, Humphreys, and Hulin: Critical reanalysis of Barrett, Caldwell, and Alexander. Personnel Psychology, 42, 597-612.

Barrett, G. V., Caldwell, M. S., \& Alexander, R. A. (1985). The concept of dynamic criteria: A critical reanalysis. Personnel Psychology, 38, 41-56.

Bass, B. M. (1962). Further evidence on the dynamic character of criteria. Personnel Psychology, 15, 93-97.

Baumeister, R. F. (1991). Meanings of life. New York: Guilford Press.

Beal, D. J., Weiss, H. M., Barros, E., \& MacDermid, S. M. (2005). An episodic process model of affective influences on performance. Journal of Applied Psychology, 90, 1054-1068.

Binning, J., \& Barrett, G. V. (1989). Validity of personnel decisions: A review of the inferential and evidential bases. Journal of Applied Psychology, 74, 478-494.

Blumberg, M., \& Pringle, C. D. (1982). The missing opportunity in organizational research: Some implications for a theory of work performance. Academy of Management Review, 7(4), 560-569.

Borman, W. C. (1977). Consistency of rating accuracy and rating errors in the judgment of human performance. Organizational Behavior and Human Performance, 20(2), 238-252.

Brogden, H. E., \& Taylor, E. K. (1950). The dollar criterion: Applying the cost accounting concept to criterion construction. Personnel Psychology, 3, 133-154.

Campbell, J. P. (1990). Modeling the performance prediction problem in industrial and organizational psychology. In M. D. Dunnette, 7 L. M. Hough (Eds.), Handbook of industrial and organizational psychology ( $2^{\text {nd }}$ ed., Vol. 1, pp. 687-782). Palo Alto, CA: Consulting Psychologists Press.

Cardy, R. L., \& Dobbins, G. H. (1986). Affect and appraisal accuracy: Liking as an integral dimension in evaluating performance. Journal of Applied Psychology, 71, $672-678$ 
Cleveland, J. N., Murphy, K. R., \& Williams, R. E. (1989). Multiple uses of performance appraisal: Prevalence and correlates. Journal of applied Psychology, 74, 130-135.

Conway, J. M. (1998). Understanding method variance in multitrait-multirater performance appraisal matrices: Examples using general impressions and interpersonal affect as measured method factors. Human Performance, 11(1), 2955.

Cooper, W. H. (1981). Ubiquitous halo. Psychological Bulletin, 90, 218-244.

Dalal, R. S., Bonaccio, S., Highhouse, S., Ilgen, D. R., Mohammed, S., \& Slaughter, J. E. (2010). What if industrial-organizational psychology decided to take workplace decisions seriously. Industrial and Organizational Psychology, 3(4), 386-405.

Deadrick, D. L., Bennett, N., \& Russell, C. J. (1997). Using hierarchical linear modeling to examine dynamic performance criteria over time. Journal of Management, 23(6), 745-757.

DeNisi, A. S., Cafferty, T., \& Meglino, B. (1984). A cognitive view of the performance appraisal process: A model and research propositions. Organizational Behavior and Human Performance, 33, 360-396.

DeNisi, A. S., \& Stevens, G. E. (1981). Profiles of performance, performance evaluations, and personnel decisions. The Academy of Management Journal, 24(3), 592-602.

Edwards, J. R., \& Lambert, L. S. (2007). Methods for integrating moderation and mediation: A general analytical framework using moderated path analysis. Psychological Methods, $12(1), 1-22$.

Ensher, E. A., \& Murphy, S. E. (1997). Effects of race, gender, perceived similarity and contact on mentor relationships. Journal of Vocational Behavior, 50, 460-481.

Feldman, J. M. (1981). Beyond attribution theory: Cognitive processes in performance appraisal. Journal of Applied Psychology, 66, 127-148.

Feldman, S. (1966). Motivational aspects of attitudinal elements and their place in cognitive interactions. In S. Feldman (Ed.), Cognitive consistency: Motivational antecedents and behavioral consequences (pp. 75-108). New York: Academic Press.

Fisher, C. D. (2008). What if we took within-person performance variability seriously. Industrial and Organizational Psychology, 1, 185-189.

Fisher, C. D., \& Noble, C. S. (2004). A within-person examination of correlates of performance and emotions while working. Human Performance, 17(2), 145- 
168.

Flanagan, J. C. (1959). The evaluation of methods in applied psychology and the problem of criteria. Occupational Psychology, 30, 1-9.

Fletcher, G., O., Danilovics, P., Fernandez, G., Peterson, D., \& Reeder, G., D. (1986). Attributional complexity: An individual differences measure. Journal of Personality and Social Psychology, 51(4), 875-884.

Frankl, V. E. (1963). Man's search for meaning: An introduction to logotherapy. New York: Washington Square Press.

Freyd, M. (1923). The graphic rating scale. Journal of Educational Psychology, 14, 83102.

Gaudet, F. J. (1963). Solving the problems of employee absence. New York: American Management Association.

Ghiselli, E. E. (1959). Dimensional problems of criteria. Journal of Applied Psychology, 1, 46-60.

Ghiselli, E. E., \& Brown, C. W. (1947). Learning in accident reduction. Journal of Applied Psychology, 31, 580-582.

Gilbert, D. T., \& Malone, P. S. (1995). The correspondence bias. Psychological Bulletin, 117(1), 21-38.

Gilbert, D. T., Pelham, B. W., \& Krull, D. S. (1988). On cognitive busyness: When person perceivers meet persons perceived. Journal of Personality and Social Psychology, 54(5), 733-740.

Green, S. G., \& Mitchell, T. R. (1979). Attributional processes of leaders in leadermember interactions. Organizational Behavior and Human Performance, 30, 109131.

Hayes, A. F. (2012). PROCESS: A versatile computational tool for observed variable moderation, mediation, and conditional process modeling. Unpublished Manuscript.

Hayes, A. F., \& Preacher, K. J. (2012). Conditional process modeling: Using structural equation modeling to examine contingent causal processes. To appear in G. R. Hancock, \& R. O. Mueller (Eds.) Structural equation modeling: A second course (2nd Ed). Greenwich, CT: Information Age Publishing.

Heider, F. (1958). The psychology of interpersonal relations. Hillsdale, NJ, US: Lawrence Erlbaum Associates. 
Highhouse, S. (2009). Designing experiments that generalize. Organizational Research Methods, 12, 554-566.

Highhouse, S., \& Gillespie, J. Z. (2009). Do samples really matter that much? In C. E. Lance \& R. J. Vandenberg (Eds.), Statistical and methodological myths and urban legends: Doctrine, verity and fable in the organizational and social sciences (pp. 247-265). New York: Routledge.

Hofmann D. A., Jacobs R., \& Baratta J. E. (1993) Dynamic criteria and the measurement of change. Journal of Applied Psychology, 78(2), 194-204.

Hoffmann, D. A., Jacobs, R., \& Gerras, S. J. (1992). Mapping individual performance over time. Journal of Applied Psychology, 77, 185-195.

Hulin, C. L., Henry, R. A., \& Noon, S. L. (1990). Adding a dimension: Time as a factor in the generalizability of predictive relationships. Psychological Bulletin, 107, 328-340.

Ilgen, D. R., \& Feldman, J. M. (1983). Performance appraisal: A process focus. In L. Cummings, \& B. Staw (Eds.), Research in organizational behavior (Vol. 5). Greenwich, CT: JAI Press.

Jones, E. E., \& Davis, K. E. (1966). From Acts To Dispositions The Attribution Process In Person Perception. In B. Leonard (Ed.), Advances in Experimental Social Psychology (Vol. 2, pp. 219-266): Academic Press.

Jones, G. V. (1979). A generalized polynomial model for perception of exponential series. Perception and Psychophysics, 25, 232-234.

Kahneman, D., \& Tversky, A. (1973). On the psychology of prediction. Psychological Review, 80, 237-251.

Kahneman, D., Fredrickson, B. L., Schreiber, C. A., \& Redelmeier, D. A. (1993). When more pain is preferred to less: Adding a better end. Psychological Science, 4, 401405.

Kaufman, H. G. (1972). Relations of ability and interest to currency of professional knowledge among engineers. Journal of Applied Psychology, 56, 495-499.

Kelley, H. H. (1972). Causal schemata and the attribution process. In E. Jones, D. Kanouse, H. Kelley, R. Nisbett, S. Valins, \& B. Weiner (Eds.), Attribution: Perceiving the causes of behavior. Morristown, NJ: General Learning Press.

Kelley, H. H. (1973). The process of causal attribution. American Psychologist, 28, $107-$ 128. 
Knowlton, W. A. \& Mitchell, T. R. (1980). Effects of causal attributions on a supervisor's evaluation of subordinate performance. Journal of Applied Psychology. 65(4), 459-466.

Landy, F. J. (2008). Stereotypes, bias, and personnel decisions: Strange and stranger. Industrial and Organizational Psychology, 1, 379-392.

Landy, F. J., \& Conte, J. M. (2009). Work in the $21^{\text {st }}$ century: An introduction to industrial and organizational psychology $\left(3^{\text {rd }} \mathrm{ed}\right.$.). Malden, MA: Blackwell.

Landy, F. J., \& Farr, J. L. (1983). The measurement of work performance. New York: Academic Press.

Lee, H., \& Dalal, R. S. (2011). The effects of performance extremities on ratings of dynamic performance. Human Performance, 24(2), 99-118.

Lefcourt, H. M., von Baeyer, C. L., Ware, E. E., \& Cox, D. J. (1979). The multidimensional-multiattributional causality scale: The development of a goal specific locus of control scale. Canadian Journal of Behavioural Science, 11(4), 286-304. doi: 10.1037/h0081598

Lowenstein, G., \& Prelec, D. (1991). Negative time preference. American Economic Review: Papers and Proceedings, 82(2), 347-352.

Lowenstein, G., \& Prelec, D. (1993). Preferences for sequences of outcomes. Psychological Review, 100, 91-108.

MacKinnon, D. P., Lockwood, C. M., Hoffman, J. M., West, S. G., \& Sheets, V. (2002). A comparison of methods to test mediation and other intervening variable effects. Psychological Methods, 7(1), 83-104.

MacKinnon, D. P., Lockwood, C. M., \& Williams, J. (2004). Confidence Limits for the Indirect Effect: Distribution of the Product and Resampling Methods. Multivariate Behavioral Research, 39(1), 99-128.

Martkino, M. J., Harvey, P., Douglas, S. C. (2007). The role, function, and contribution of attribution theory to leadership: A review. The Leadership Quarterly, 18, 561585.

Miner, A. G., \& Glomb, T. M. (2010). State mood, task performance, and behavior at work: A within-person approach. Organizational Behavior and Human Decision Processes, 112, 43-57.

Muller, D., Judd, C. M., \& Yzerbyt, V. Y. (2005). When mediation is moderated and 
moderation is mediated. Journal of Personality and Social Psychology, 89, 852863.

Murphy, K. R., Balzer, W. K., Lockhart, M. C., \& Eisenman, E. J. (1985). Effects of previous job performance on evaluations of present performance. Journal of Applied Psychology, 70, 72-84.

Murphy, K. R., \& Cleveland, J. N. (1995). Understanding performance appraisal: Social, organizational and goal-based perspectives. Thousand Oaks, CA: Sage.

Nagle, B. (1953). Criterion development. Personnel Psychology, 6, 271-289.

Nieminen, L. R. G., Rudolph, C. W., Baltes, B. B., Capser, C., Wynne, K. T., \& Kirby, L. C. (2013). The combined effects of contextual information and ratee bodyweight on performance judgments. Journal of Applied Social Psychology, 43(3), 527-543.

Paterson, D. G. (1923). Methods of rating human qualities. Annals of the American Academy of Political Social Science, 110, 81-93.

Ployhart, R. E., \& Hakel, M. D. (1998). The substantive nature of performance variability: Predicting interindividual differences in intraindividuial performance. Personnel Psychology, 51, 859-901.

Porter, L. W. Crampon, W. J., \& Smith, F. S. (1976). Organizational commitment and managerial turnover: A longitudinal study. Organizational Behavior and Human Performance, 15, 87-98.

Preacher, K., \& Hayes, A. (2004). SPSS and SAS procedures for estimating indirect effects in simple mediation models. Behavior Research Methods, 36(4), 717-731.

Preacher, K., \& Hayes, A. (2008). Asymptotic and resampling strategies for assessing and comparing indirect effects in multiple mediator models. Behavior Research Methods, 40(3), 879-891.

Rambo, W. W., Chomiak, A. M., \& Price, J. M. (1983). Consistency of performance under stable conditions of work. Journal of Applied Psychology, 68, 78-87.

Reb, J., \& Cropanzano, R. (2007). Evaluating dynamic performance: The influence of salient Gestalt characteristics on performance ratings. Journal of Applied Psychology, 92(2), 490-499.

Reb, J., \& Greguras, G. J. (2008). Dynamic performance and the performance, performance rating relation. Industrial and Organizational Psychology: Perspectives on Science and Practice, 1(2), 194-196. 
Reb, J., \& Greguras, G. J. (2010). Understanding performance ratings: Dynamic performance, attributions, and rating purpose. Journal of Applied Psychology, 95(1), 213-220.

Roby, T. B. (1963). Behavioral freedom and constraint. Journal of Psychological Studies, 14(2), 49-69.

Rothe, H. F. (1978). Output rates among industrial employees. Journal of Applied Psychology, 63, 40-46.

Russell, J. A. (1980). A circumplex model of affect. Journal of Personality \& Social Psychology, 39, 1161-1178.

Scott, W. E., \& Hamner, W. C. (1975). The influence of variations in performance profiles on the performance evaluation process: An examination of the validity of the criterion. Organizational Behavior and Human Performance, 14(3), 360-370.

Sherif, M., \& Cantril, H. (1945). The psychology of attitudes. Psychological Review, 52, 295319.

Shrout, P. E., \& Bolger, N. (2002). Mediation in experimental and nonexperimental studies: New procedures and recommendations. Psychological Methods, 7(4), 422-445.

Smither, J. W., Reilly, R. R., \& Buda, R. (1988). Effect of prior performance information on ratings of present performance: Contrast vs. assimilation revisited. Journal of Applied Psychology, 73, 487-496.

Sobel, M. E. (1982). Asymptotic confidence intervals for indirect effects in structural equation models. American Sociological Association, 13, 290-312.

Stewart G. L., \& Nandkeolyar, A. K. (2006). Adaptation and intraindividual variation in sales outcomes: Exploring the interactive effect of personality and environmental opportunity. Personnel Psychology, 59, 307-332.

Stewart, G. L., \& Nandkeolyar, A. K. (2007). Exploring how constraints created by other people influence intraindividual variation in objective performance measures. Journal of Applied Psychology, 92, 1149-1158.

Sturman, M. C., Cheramie, R. A., \& Cashen, L. H. (2005). The impact of job complexity and performance measurement on the temporal consistency, stability, and testretest reliability of employee job performance ratings. Journal of Applied Psychology, 90, 269-283.

Surber, C. F. (1984). Inferences about ability and effort: Evidence for two different processes. Journal of Personality and Social Psychology, 46, 249-268. 
Tabachnick, B. G., \& Fidell, L. S. (2012). Using multivariate statistics, $6^{\text {th }}$ ed. Boston: Allyn and Bacon.

Thoresen, C. J., Bradley, J. C., Bliese, P. B., \& Thoresen, J. D. (2004). The Big Five personality traits and individual job performance growth trajectories in maintenance and transitional job stages. Journal of Applied Psychology, 89, 835853.

Thorndike, R. L. (1949). Personnel selection: Test and measurement techniques. New York, NY: Wiley.

Tjosvold, D. (1985). The effects of attribution and social context on superiors' influence and interaction with low performance subordinates. Personnel Psychology, 38, 361-376.

Troops, H. A. (1944). The criterion. Educational and Psychological Measurement, 4, 271-297.

Tucker, M. F., Cline, V. B., \& Schmitt, J. R. (1967). Prediction of creativity and other performance measures from biographical information among pharmaceutical scientists. Journal of Applied Psychology, 51, 131-138.

Turban, D. B., \& Jones, A. P. (1988). Supervisor-subordinate similarity: Types, effects, and mechanisms. Journal of Applied Psychology, 73, 228-234.

Viswesvaran, C., \& Ones, D.S. (2000). Perspectives on models of job performance. International Journal of Selection and Assessment, 8, 216-226.

Waldmann, M. R. (2007). Combining versus analyzing multiple causes: How domain assumptions and task context affect integration rules. Cognitive Science, 31, 233256.

Weiner, B. (1995). Judgments of responsibility: A foundation of a theory of social conduct. New York: Guilford Press.

Weiner, B., \& Kukla, A. (1970). An attributional analysis of achievement motivation. Journal of Personality and Social Psychology, 15(1), 1-20.

Weiner, B., Frieze, I., Kukla, A., Reed, L., Rest, S., \& Rosenbaum, R. (1972). Perceiving the causes of success and failure. In E. Jones, D. Kanouse, H. Kelley, R. Nisbett, S. Valins, \& B. Weiner (Eds.), Attribution: Perceiving the causes of behavior. Morristown, NJ: General Learning Press.

Wherry, R. J., \& Bartlett, C. J. (1982). The control of bias in ratings: a theory of rating. Personnel Psychology, 35, 521-551 
Wherry, R. J., \& Fryer, D. H. (1949). Buddy rating: Popularity contest or leadership criteria? Personnel Psychology, 2, 147-159.

Wyer, R. S., \& Hinkle, R. L. (1971). Informational factors underlying inferences about hypothetical persons. Journal of Personality and Social Psychology, 34, 481-495.

Zyphur, M. J., Chaturvedi, S., \& Arvey, R. D. (2008). Job performance over time is a function of latent trajectories and previous performance. Journal of Applied Psychology, 93(1), 217-224. 


\section{Appendix A}

Cued disposition manipulation.

\begin{tabular}{|l|l|}
\hline \multicolumn{2}{|c|}{ 2012 Performance Appraisal Form } \\
\hline Employee: & Chris Williams \\
\hline $\begin{array}{l}\text { Manager } \\
\text { Comments: }\end{array}$ & (Vignette inserted here) \\
& \\
\hline
\end{tabular}

\begin{tabular}{|c|c|}
\hline High Ability - High Effort & $\begin{array}{l}\text { Chris is a talented employee and has an exceptionally } \\
\text { high aptitude for this position. Additionally, his } \\
\text { determination and personal drive is evident. Overall, he } \\
\text { is a competent employee, who demonstrates } \\
\text { considerable ambition. }\end{array}$ \\
\hline High Ability - Low Effort & $\begin{array}{l}\text { Chris is a talented employee and has an exceptionally } \\
\text { high aptitude for this position. However, his lack of } \\
\text { determination and personal drive is evident. Overall, he } \\
\text { is a competent employee, who demonstrates relatively } \\
\text { little ambition. }\end{array}$ \\
\hline Low Ability - High Effort & $\begin{array}{l}\text { Chris is not a talented employee and has an } \\
\text { exceptionally low aptitude for this position. However, } \\
\text { his determination and personal drive is evident. Overall, } \\
\text { he is an incompetent employee, who demonstrates } \\
\text { considerable ambition. }\end{array}$ \\
\hline Low Ability - Low Effort & $\begin{array}{l}\text { Chris is not a talented employee and has an } \\
\text { exceptionally low aptitude for this position. } \\
\text { Additionally, his lack of determination and personal } \\
\text { drive is evident. Overall, he is an incompetent } \\
\text { employee, who demonstrates relatively little ambition. }\end{array}$ \\
\hline
\end{tabular}




\section{Appendix B}

MOAPS Items grouped by dimension.

Responses are made on a 7-point Likert-Type scale ranging from "Strongly Disagree" to "Strongly Agree."

\begin{tabular}{lcl}
\hline Attribution & Item \# & \multicolumn{1}{c}{ Item } \\
\hline Effort & 1 & $\ldots$ reflects the effort they put into their job. \\
2 & $\ldots$ is a direct result of their efforts. \\
3 & $\ldots$ is probably due to effort on their part. \\
4 & $\ldots$ is likely influenced by their hard work. \\
5 & $\ldots$ may be due to their motivation. \\
6 & $\ldots$ has a lot to do with working hard. \\
& 7 & $\ldots$ reflects the fact that they have the ability to do their job. \\
8 & $\ldots$ is a direct result of their competence. \\
9 & $\ldots$ is probably due to their ability. \\
& 10 & $\ldots$ is likely influenced by their competence. \\
& 11 & $\ldots$ may be due to the fact that they have the talent to do their job. \\
12 & $\ldots$ has a lot to do with competence.
\end{tabular}

Note. Each items anchored with, "This person's performance... 


\section{Appendix C}

Subjective performance rating scale.

Responses are made on a 7-point Likert-Type scale ranging from "Strongly Disagree" to "Strongly Agree."

\begin{tabular}{|cl|}
\hline Item \# & Item \\
\hline 1 & $\begin{array}{l}\text { In general, how would you characterize the performance of the sales manager whom you just } \\
\text { rated? }\end{array}$ \\
\hline 2 & $\begin{array}{l}\text { Considering their performance, what is your overall impression of the sales manager whom } \\
\text { you just rated? }\end{array}$ \\
\hline 3 & Overall, how would you rate this person's performance as a sales manager? \\
\hline
\end{tabular}


Appendix D

Experimental manipulations
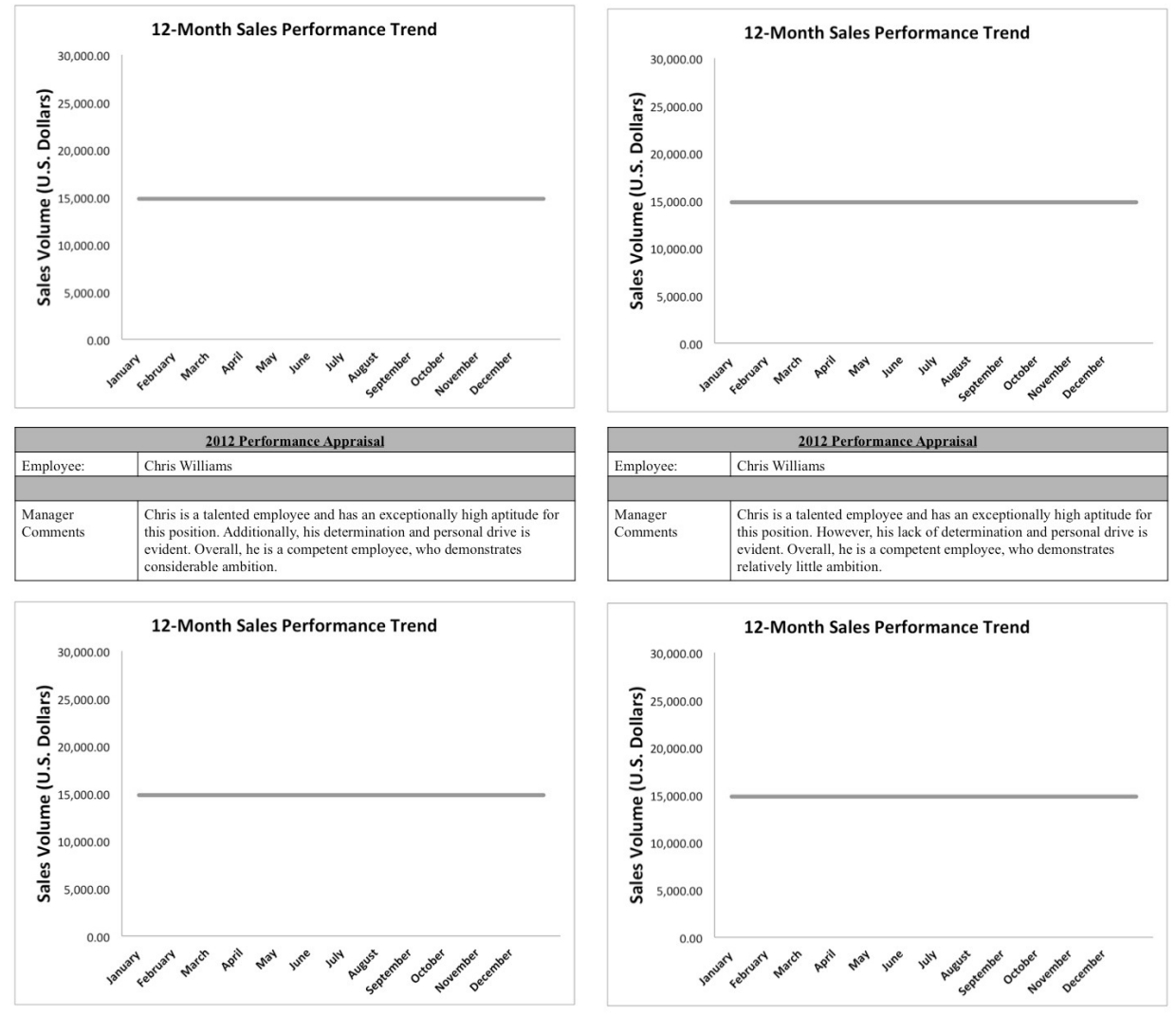

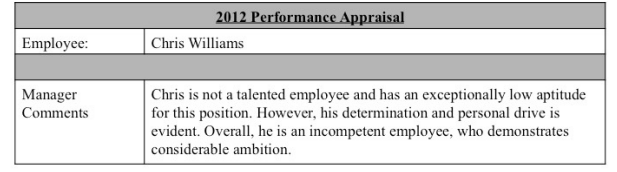

\begin{tabular}{|l|l|}
\hline \multicolumn{2}{|c|}{ 2012 Performance Appraisal } \\
\hline Employee: & Chris Williams \\
\hline \multicolumn{2}{|c|}{} \\
\hline $\begin{array}{l}\text { Manager } \\
\text { Comments }\end{array}$ & $\begin{array}{l}\text { Chris is not a talented employee and has an exceptionally low aptitude } \\
\text { for this position. Additionally, his lack of determination and personal } \\
\text { drive is evident. Overall, he is an incompetent employee, who } \\
\text { demonstrates relatively little ambition. }\end{array}$ \\
\hline
\end{tabular}
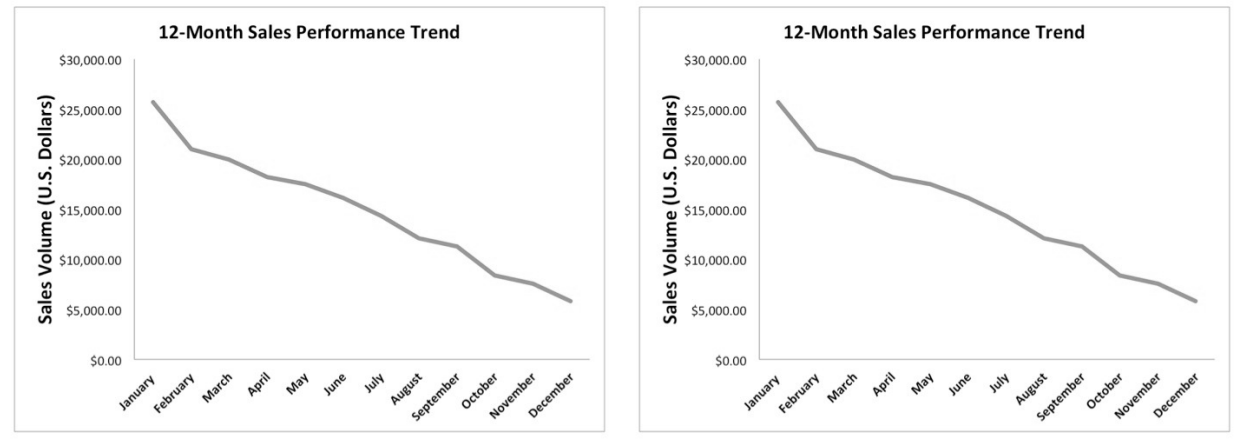

\begin{tabular}{|l|l|}
\hline \multicolumn{2}{|c|}{ 2012 Performance Appraisal } \\
\hline Employee: & Chris Williams \\
\hline \multicolumn{2}{|c|}{} \\
\hline $\begin{array}{l}\text { Manager } \\
\text { Comments }\end{array}$ & $\begin{array}{l}\text { Chris is a talented employee and has an exceptionally high aptitude for } \\
\text { this position. Additionally, his determination and personal drive is } \\
\text { evident. Overall, he is a competent employee, who demonstrates } \\
\text { considerable ambition. }\end{array}$ \\
\hline
\end{tabular}

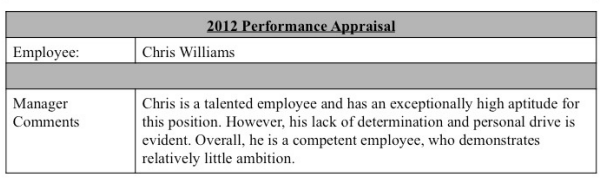

86 
Experimental manipulations (continued)
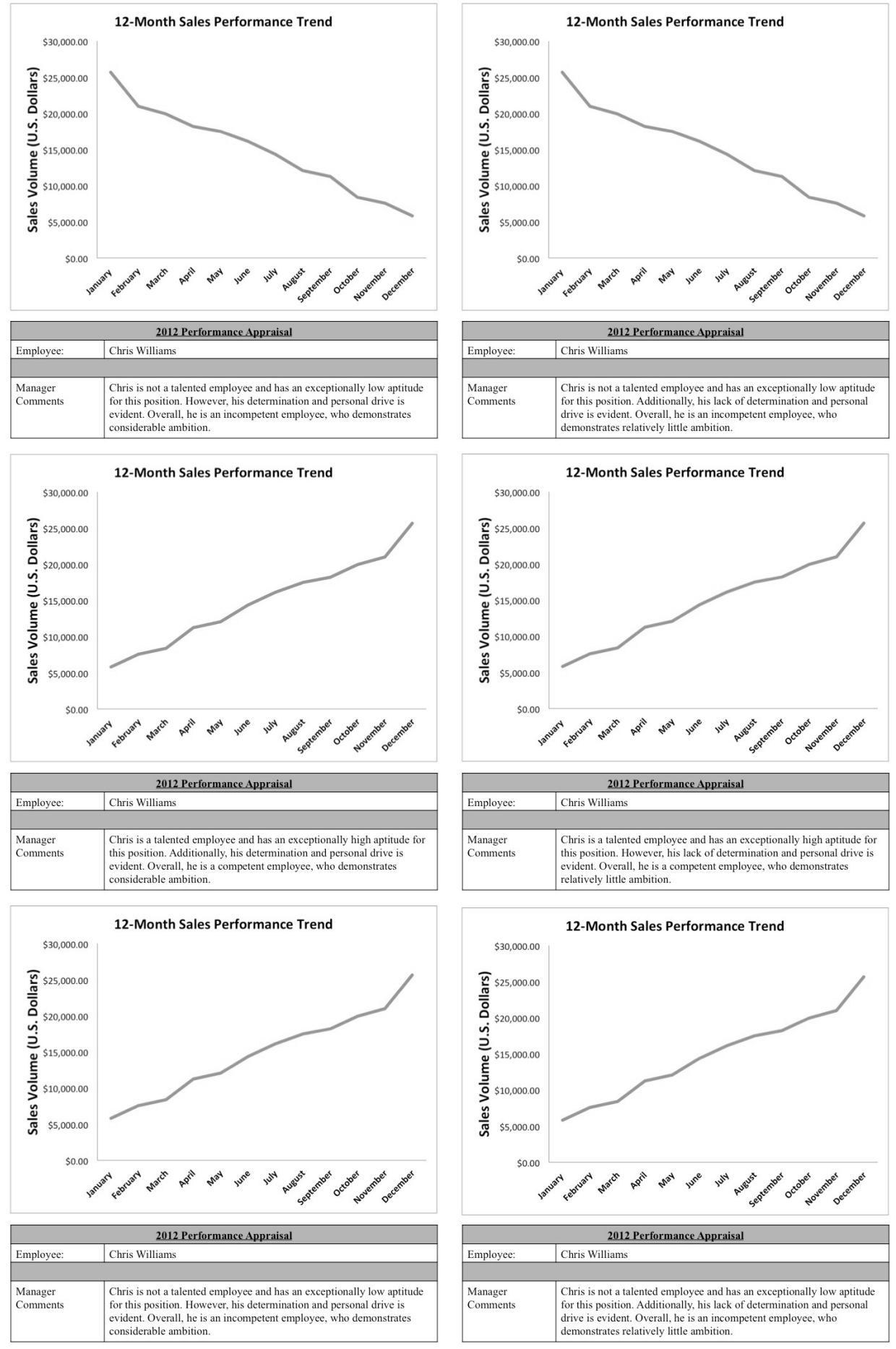

87 